\title{
An overview of the results of the volcano geodetic research in
}

\section{the Canary Islands.}

\author{
José Fernández ${ }^{(1, *)}$, Pablo J. González ${ }^{(2)}$, Antonio G. Camacho ${ }^{(1)}$, \\ Juan F. Prieto ${ }^{(3)}$, and Guadalupe Brú ${ }^{(1)}$ \\ ${ }^{(1)}$ Institute of Geosciences (IGEO) (CSIC, UCM), Plaza de Ciencias 3, 28040-Madrid, Spain. \\ ${ }^{(2)}$ Institute of Geophysics and Tectonics, School of Earth and Environment, University of Leeds, \\ Leeds - LS2 9JT, United Kingdom. \\ ${ }^{(3)}$ Department of Engineering Surveying and Cartography, School of Eng. Surveying, Geodesy \\ and Cartography, Technical University of Madrid, Spain.
}

SHORT TITLE: VOLCANO GEODETIC RESEARCH IN THE CANARY ISLANDS

${ }^{(*)}$ Corresponding author: E-mail: jft@mat.ucm.es 


\begin{abstract}
Canary Islands are mostly characterized by diffuse and scattered volcanism affecting a million people live and work in the $7,447 \mathrm{~km}^{2}$ of the archipelago, resulting in an average population density three times greater than the rest of Spain. This fact, together with the growth in exposure in the past 40 years, increases the volcanic risk with respect to the situation of the previous eruptions, as witnessed during the recent 2011-2012 El Hierro submarine eruption. Therefore, in addition to purely scientific reasons, there are economic and population-security reasons for developing and maintaining an efficient volcano monitoring system. In this scenario, geodetic monitoring represents an important part of this monitoring system. We describe the research in volcano geodetic monitoring carried out in the Canary Islands and the results obtained. We consider for each epoch the two main constraints existing: the level of volcanic activity in the archipelago and the limitations of the techniques available at the time. Theoretical and observational aspects are considered, as well as the implications on operational volcano surveillance. Current challenges and future perspectives in the geodetic volcano monitoring in the Canaries are also presented.
\end{abstract}

Keywords: Canary Islands; Volcanic activity; Volcano geodesy; Deformation and gravity change; Space and terrestrial techniques; deformation modeling and inversion techniques. 


\section{Introduction.}

Large volcanic eruptions are usually associated with polygenetic volcanoes where recurrent events occur in the same volcanic edifice. In these cases, the area to be monitored can be relatively well defined. However, a challenging scenario occurs when diffuse and scattered volcanism affects a large area. Canary Islands volcanism is mostly characterized by the second scenario, Figure 1, where there is only an active stratovolcano (Teide-Pico Viejo complex, Tenerife), but predominantly the historical activity occurred in more frequent monogenetic cones along elongated rifts (Fernández et al. 1999; 2003).

One must consider the population (more than 2 million people) living in the archipelago (giving a population density, in its $7,447 \mathrm{~km} 2$, three times greater than for the rest of Spain), the level of economic activites, together with the growth in exposure in the last decades which increases volcanic risk with respect to the situation of the previous eruptions (e.g. 1971 Teneguía eruption in La Palma), as shown by the recent 2011-2012 El Hierro submarine eruption. In consequence, apart from the purely scientific reasons, there are economic and security issues for the population which obligate to develop and maintaining an efficient volcano monitoring system. The traditional geochemical and geophysical observations of seismic, hydrological or fumarolic activity have proved to be very useful in volcano monitoring, and are usually the core of operative volcano monitoring systems. Seismic observation involves distributing a series of seismic sensors around the volcano, or area to be monitored, and automatically sending your log data to a control center that stores and processes it (Quaas et al., 1996). Seismic monitoring is useful for locating volcanic and/or tectonic sources and monitoring and evaluating their temporal evolution. Perhaps the closest example of this surveillance has been the location of the source of submarine volcanic eruption of El Hierro which began in October 2011 (http://www.ign.es/ign/resources/volcanology/HIERRO.html). Geodetic monitoring is an integral 
part of this monitoring system, complementing different seismic, geophysical and geochemical techniques (see e.g., Sigurdsson et al., 2000, Dzurisin, 2007; Pérez and Hernández, 2008).

This review describes the evolution of geodetic research with emphasis on volcano monitoring in the Canary Islands. We review the main methodological and observational results achieved since the 20th century, as well as the implications of these results on operational volcano surveillance in every epoch. We also present some new unpublished deformation results for Tenerife and Fuerteventura Islands.

\section{Geological and volcanic framework.}

The Canary Islands are located in the northwestern part of the Nubian (African) tectonic plate, relatively far from major plate boundaries and close to the thickened Western African craton continental lithosphere. The Canary Islands are a group of seven major islands forming a rough East-West trending archipelago (Figure 1). The latter forms part of a large group of magmatic plateaus, together with the Selvagen Islands, several seamount complexes, and the Madeira group (CGMW, 2010). This magmatic province sits on Jurassic-age (150-180 Ma) oceanic lithosphere, implying a relatively cold, strong and thick lithosphere. The archipelago is located on the transitional zone, a passive margin, between oceanic and continental crust (e.g., Banda et al 1981; Suriñach et al 1986). These, in conjunction with a slow moving plate, have important implications on the partial melting of the mantle underneath the Canary Islands and contribute to a geodynamic scenario that has been extremely complex to uncover.

Since the inception of the hot spots theory (Morgan, 1971), the Canary Islands have been attributed to this origin. However, some unusual features in their geochemistry, the influence of Atlas tectonics and lithosphere structure (absence of gravity and bathymetry anomalies) raised questions on the full validity of this hypothesis, calling for hybrid geodynamic scenarios (Anguita 
and Hernán, 2000 and reference therein).

The Canary Islands shows an age progression in dated rocks, from FuerteventuraLanzarote in the East to El Hierro Island in the West (Figure 1). In general, older islands have clearer evidence for longer erosional periods and flank collapse processes. Indeed, the easternmost and oldest islands of Fuerteventura and Lanzarote are the lowest with elevations below $1000 \mathrm{~m}$. Their sub-aerial volcanism started around 20-15 Ma, with little evidence of scattered-diffuse Quaternary volcanism. Gran Canaria, Tenerife and La Gomera could be classified as of intermediate-age with Miocene ages of 14.5, 11.9, 9.4 Ma, respectively (Hoernle and Carracedo, 2009). This subgroup is the largest by volume, with Tenerife rising $~ 7000 \mathrm{~m}$ from the surrounding seafloor. A unique characteristic are the voluminous erupted phonolite deposits, a highly differentiated and relatively high-silica content rock in Gran Canaria and Tenerife. In Gran Canaria and La Gomera, more deeply eroded, outcrop intrusive complexes and dike swarms, e.g., Vallehermoso and Tejeda, respectively (Ancoechea et al., 2003). Finally, the youngest group is La Palma and El Hierro, which started forming in the last $4 \mathrm{Ma}$, and only emerged above sea level in the last $2 \mathrm{Ma}$. Both Islands are in a highly rapid growing stage with frequent basaltic eruption along structural rifts.

Contrasting with the hot spot theory, recent Holocene volcanism is spread over archipelago, except for La Gomera and Fuerteventura. Consistently, Lanzarote, Tenerife, La Palma and El Hierro have erupted during the last 500 years. A total of 19 historical subaerial eruptions have been recorded in the Canary Islands (Siebert et al., 2011). The most voluminous eruption took place, 1730-1736, in Lanzarote (second oldest), the last on-shore eruption was at Teneguía Volcano (La Palma) in 1971 (Romero, 2000) and the most recent was submarine on the island of El Hierro in 2011-2012 (Carracedo et al, 2012; López et al, 2012, González et al, 2013).

Regarding the kinematics of the archipelago, some moderate earthquakes have been registered in the Canary Islands region, which could be attributed to a diffuse tectonic activity, 
e.g., the M5.2 1989 Tenerife-Gran Canaria earthquake (Mezcua et al., 1992) and the M6.2 1959

Atlantic ocean earthquake (Wysession et al., 1995). However, there is no evidence of significant crustal strain accumulation around the Canary Islands. Moreover, considering the age of the volcanism, and the location of the volcanic seamounts and islands, the observed age progression could be explained by a rotation of the Nubian plate with respect to a fixed point beneath the lithosphere mantle (supporting a mantle plume). The location and age of volcanism can be described with an Euler rotation pole at approximately $56.8 \mathrm{~N}, 45.8 \mathrm{~W}$, with an angular rate of 0.20 degrees/Ma using ages from 0-35 Ma. Conversely using ages for the interval 35-64 Ma, the African plate was rotating with respect to the fixed point with a different Euler pole located at 35.8 N, 45.8 W (Geldmacher et al., 2005).

Another important observation regarding the kinematics is the vertical (uplift-subsidence) longterm motions. As part of growth of an intraplate oceanic island, the lithosphere under the mantle source should undergo relative uplift, followed by a subsidence after passing though the mantle source, which eventually leads to the formation of seamount (guyots). None of the Canary Islands show significant subsidence processes, although guyots can be observed in bathymetric maps around the archipelago (Figure 1). In contrast, most of the islands show significant uplift histories with outcropping seamount volcanoes in La Palma and Fuerteventura (Hoernle and Carracedo, 2009), but whether it reflects endogenous growth or regional uplift has not been resolved yet. On shorter time scales, in Lanzarote, Fuerteventura, and Tenerife there are also Quaternary-dated raised beaches at different elevations (Zazo et al., 2002; Kröchert et al., 2008). 


\section{Volcano geodetic studies in the canaries during the 20th century.}

Until recent decades, Canarian volcanism has only been studied using geological, geophysical and geochemical techniques, little attention being paid to geodetic measurements, especially for volcano monitoring aspects. Since the 1980s, several projects include the application, study, development or/and validation of different geodetic techniques and methods of observation for volcanic monitoring. The research has covered both the observational and theoretical aspects of detecting and interpreting deformation and gravity changes, as well as methods to determine crustal structure from gravity observations, a basic tool for interpretation of observed gravity anomalies.

The temporal evolution and spatial coverage of the research in geodetic volcano monitoring had two basic constraints: a) the level of volcanic activity in the archipelago and b) the limitations of the techniques available at the time. The level of volcanic activity was greatly reduced after the Teneguía eruption on the island of La Palma in 1971 (Araña and Fúster, 1974; Hernández-Pacheco and Vals, 1982). Generally, the low levels of detected volcanic activity result in fewer efforts being made to investigate the background levels of geophysical, geochemical and geodetic parameters. Accordingly, in the last decades of the 20th century, scientific and observational works focused on the islands of greatest potential risk (Tenerife, La Palma) or offering the best facilities for developing and maintaining research instruments (Lanzarote). Furthermore, the characteristics of classical geodetic observations and instruments (leveling, triangulation, trilateration, gravimetry, etc.) available at that time (late 1970's to 2000) (Fernández et al., 1999) made it time-consuming and expensive to cover the whole surface of the Islands.

On account of all those constraints, investigations using classical geodetic techniques were conducted with very limited spatial coverage, trying to reduce the observational costs to a 
reasonable amount consistent with the level of volcanic activity and the real risk. This is the case Lanzarote.

\subsection{Earliest studies.}

Scientific work done in the $20^{\text {th }}$ century (before the 80 s) which can be considered related, at least in part, to the study and understanding of volcanic activity in the Canary Islands, concentrated on the design, construction and observation of a geodetic network for the realization of the geodetic reference system, and the gravity survey with structural objectives in and around several islands.

Geodetic reference frame: The first geodetic project with scientific quality in the Canary Islands dated back to the 1920s, and sought to materialize a geodetic reference frame. In 1923 (Gil Montaner, 1929a), the Instituto Geografico y Estadístico (IGE) designed a geodetic network covering the whole Archipelago, that was observed between 1925 and 1928, using classical observation techniques of angles and distances (Torroja, 1926). The project included a large network, with first-order specifications, covering the seven main islands, and other filling networks inside the islands with second and third order specifications (Caturla, 1996). Spatial configuration of this network is shown in Figure 2.

Gil Montaner (1929b) reported the geodetic link of the Canarian archipelago with the African continent at Cabo Juby (Morocco). All observations were completed in 1930 (Caturla, 1996) and the triangulation chain was finally adjusted by means of least squares fit in 1936 (IGC, 1938). Astronomical coordinates from the trigonometric point at Pico de las Nieves in Gran Canaria were used to start the computations. This is the reason why the geodetic reference frame embodying this network is known as datum "Pico de las Nieves 1930". The Greenwich meridian 
was selected as the origin of latitudes, this being the first time this meridian was used in Spain, along with the Hayford ellipsoid (Hayford, 1910). In 1968, a joint computation of the main network of 1930 was performed together with the islands' second and third order networks (IGC, 1938) to obtain a single framework for the entire archipelago. This new calculation, which did not include any new observations, constitutes the geodetic frame named "Pico de las Nieves 1968” (PN68).

In the period 1976-1978, the Instituto Geográfico Nacional (IGN) conducted doppler satellite observations for TRANSIT (Navy Navigation Satellite System, NNSS) system (Caturla, 1978). The geodetic points of La Laguna in Tenerife, Maspalomas in Gran Canaria and Toston in Fuerteventura, were joined by very long baselines with Villafranca and San Fernando stations on the Iberian Peninsula. These geodetic observations were the first to tie the islands with the mainland. Coordinate calculations were performed in the WGS72 geodetic reference system achieving a submeter accuracy.

In 1982, IGN began to define a new geodetic network reusing some ancient monuments and densifying the previous networks, using classical observations by triangulation and distance measurement with laser geodimeter (Caturla, 1996). The Tenerife, La Palma, La Gomera and El Hierro island networks were thus completed, forming the geodetic frame called "Pico de las Nieves 1984" (PN84). During the 1990s, observation of the networks in Gran Canaria, Lanzarote and Fuerteventura was completed. The networks of these three islands were no longer computed in the new geodetic frame PN84, because a new GNSS geodetic network was projected for the Canary Islands (Barbadillo-Fernández and Quirós-Donate, 1996).

The GPS network consisted of a regional network linking the seven main islands and the corresponding inner geodetic networks in each of them. The regional network consisted of 12 stations spread throughout the islands starting with the IGS CORS station in Maspalomas 
(MASP), and is computed (Barbadillo-Fernández and Quirós-Donate, 1996; Caturla, 1996) under

ITRF93, epoch 1994.9. Immediately thereafter, a GNSS network was observed and computed for each island, making a total of 296 stations, which form the geodetic frame "REGCAN95". Using these GNSS stations, a recalculation of the former networks of angular observations and distances previously observed (Caturla, 1996) was performed, thus completing the new geodetic network for the Canary Islands. In this phase, orthometric heights were computed for each geodetic point by the trigonometric leveling method. IGN also conducted precise leveling profiles throughout the islands, referred to mean sea level in each of the islands. Caturla and Prieto (1996) computed the transformation parameters between the four different geodetic frames that have existed in the Canary Islands since 1930.

Structural gravimetry: In 1965, 1967 and 1968, the Department of Geophysics at Imperial College, University of London, conducted the first marine and terrestrial seismic and gravimetric observation experiments in the Canary Islands. In 1965, ground gravity data were measured on the islands of Lanzarote, Gran Canaria, Tenerife and El Hierro, mapping Bouguer Anomaly and allowing implementing structural models for the islands of Tenerife and Lanzarote. In 1967 and 1968, the first off-shore campaigns of marine gravimetry and seismic refraction were carried out along $2650 \mathrm{~km}$ of profiles. Although some data were taken in the eastern part of the archipelago, efforts focused more on the western part and gravity maps were published for the area of Gran Canaria, Tenerife, La Gomera, La Palma and El Hierro. The main objective of this work was to discern whether they were really oceanic Islands or rather were part of the African continent.

MacFarlane and Ridley (1968) were the first to interpret on-shore gravity anomalies in Tenerife and, based on a small number of stations, they identified a strong positive gravimetric anomaly south of Teide. This maximum was interpreted as bring due to a very dense, conicalshaped intrusive body (whose density increases with depth from 2800 to $3100 \mathrm{~kg} / \mathrm{m} 3$ ), stretching 
from the Moho to about $4 \mathrm{~km}$ below the surface. They also detected in the gravity map the pattern

of three major fracture systems at 120 degrees to each other, of which two were already known from geological field studies.

For Lanzarote Island, the first interpretation of terrestrial gravity anomalies was described by MacFarlane and Ridley (1969). They also consider preliminary seismic data (Dash and Bossard, 1969) and data from a marine gravity profile near Lanzarote. In their work, the transition position of the islands between the continental crust and the oceanic crust is concluded. The presence of a large high-density intrusive body beneath the center-south of the island, and the existence of the dominant structural direction ENE are also inferred.

Using the Imperial College seismic refraction data and gravimetry, Bosshard and MacFarlane (1970) present a comprehensive study of the mantle depth (giving values of $12 \mathrm{~km}$ west of La Palma and El Hierro, $13.9 \mathrm{~km}$ south of La Gomera and Tenerife, $15 \mathrm{~km}$ north of Tenerife and Gran Canaria, and 21-22 km under the continental shield), cortical thickness indicative of isostatic compensation, and structural models for Tenerife and Gran Canaria. They conclude that the crust in El Hierro, La Palma, La Gomera and Tenerife is essentially oceanic, while Gran Canaria is located in the transition zone between oceanic crust and continental crust. They also conclude that the islands are not part of the African continent, but are independent volcanic edifices emerged in NE-SW fracture zones.

\subsection{0s and 1990s: the rise of modern Volcano geodesy in the Canary Islands.}

\subsubsection{Structural gravimetry.}

In 1987, the United States Geological Survey (USGS) conducted a marine gravity campaign in the Canary Islands as part of a series of studies of the East Atlantic margin. This work was conducted with a good precision and the studied area is limited to a few kilometers in the sea 
around each island (Folger et al., 1990). After that, various geophysical studies including marine gravimetry have been carried out in and around the archipelago. For example, in 1993 the University of Oxford conducted a marine seismic survey that included gravimetric observations along some profiles in the archipelago (Watts et al., 1993).

Watts (1994) compiled data from 44 sea profiles and also included land data from Western African obtained by the University of Leeds in an area including the Canary Islands. He studied the lithospheric flexure in the archipelago and, by comparing seismic and free-air anomaly gravity data and elastic models, estimated values for the elastic thickness of the lithosphere and various results concerning lithospheric flexure. He concluded that the observed thinning of the oceanic lithosphere in the region would be produced by thermal disturbances which come from a mantle plume. Despite the lack of a long wavelength topographic bulge, he reaches the conclusion that the plume may be quite narrow.

Ranero et al. (1995) obtained a Free Air Anomaly map for various profiles, and in combination with seismic data, also obtained a thinning of the crust in the area, concluding that the most likely origin of the Canary Islands is a hot spot.

Subsequently, Watts et al. (1997) again worked on the same compilation of free-air gravity anomalies, also using seismic reflection data to compare the observed data with gravimetric ones calculated using a 2-D model of Tenerife Island. They present a twodimensional interpretive model of the flanks of Tenerife and adjacent crust. Their NE-SW profile shows a volcanic $2720 \mathrm{~kg} / \mathrm{m} 3$ density core, located over which are layers of density from 2480 $\mathrm{kg} / \mathrm{m} 3$ at the bottom to $2270 \mathrm{~kg} / \mathrm{m} 3$ in the top layer. They also identified around the island a flexion moat filled with sediments (with a density of $2080 \mathrm{~kg} / \mathrm{m} 3$ ).

Canales and Dañobeitia (1998), working on a new compilation of bathymetric and gravity data from marine profiles in the area, conclude the existence of a subsurface load correlated with the surface volcanic loads. The surface expression of the subsurface load is an oceanic swell 
which is detected in the anomalous shallow basement and in the residual gravity/geoid anomaly.

Yet Jung and Rabinowitz (1986), Filmer and McNutt (1989) and Watts (1994) suggest that the geophysics of the archipelago and the intervening seas is characterized by the absence of a bathymetric swell or a geoid high.

With respect to the terrestrial gravimetric data, since the 1970s different gravimetric surveys have been carried out to better define local terrestrial anomalies or highlight certain structural details in Lanzarote (Sevilla and Parra, 1975), Tenerife (Vieira et al, 1986; Camacho et al, 1991;. Ablay and Kearey, 2000; Araña et al, 2000), Fuerteventura (Montesinos, 1999), Gran Canaria (Anguita et al, 1991; Camacho et al, 2000). Advances in this line of research has been marked by three factors: (1) the emergence of GPS positioning equipment, (2) the availability of digital mapping, and (3) the increasing computing power allowing gravity inversion approaches to be more ambitious.

Indeed, GPS positioning has represented a revolution in gravimetry by obtaining the necessary precise vertical coordinates. Earlier works were limited to existing leveling lines or venturing into other areas using low levels of precision solutions, such as interpolated heights from topographic maps or inferred using barometric leveling. In the latter case, it was difficult to ensure heights with accuracies better than $10 \mathrm{~m}$.

Digital mapping has brought a breakthrough in computing the gravimetric correction produced by the relief effect, which can be very important in volcanic areas. Compared with very time-consuming determinations using Hammer abacus, the use of Digital Elevation Models (DEM) and automatic correction using computer codes allows for a quite instantaneous and very accurate determination of gravity corrections, with quality depending mainly on DEM quality and resolution (Camacho et al, 1988).

Third, the continuously improving computing capabilities of personal computers enabled the development of non-subjective methodologies for linear and non-linear gravity inversion, to 
construct 3D models of anomalous density contrasts. The models consisting of thousands of

model resolution elements (see e.g., Camacho et al, 2000). These approaches contrast with the previous ones based on direct computations and testing. These methods started to be developed during the 1990s. The time evolution can be seen in Figure 3.

\subsubsection{Measurement of deformation and gravity changes.}

During the 1980s and 1990s, deformation and gravity variation measurements were carried out on several Islands. Moreover, the improvement of gravimetric instruments and, above all, the chances of very precise altimetry control have led to an interesting application of gravimetry in the geodetic control of volcanic phenomena: the microgravimetric detection and interpretation of gravity variations (in the sense of measuring with high precision gravity time variation and interpreting them to obtain characteristics of magmatic processes) (e.g., Sidgursson et al., 2000; Dzurisin, 2007; Battaglia et al., 2008). However, this technique would not apply in the Canary Islands until the increase of volcanic activity necessitated its use in the $21^{\text {st }}$ Century (see next section).

Tenerife Island: The realization that the Las Cañadas Caldera and the Teide volcano was one of the largest risk areas in the Canary Islands (Araña and Gómez, 1995) resulted in most volcano research being focused there, in particular all the geodetic studies.

At the beginning of the 1980s, a 17-benchmark classical geodetic micro-network was designed and set up in the Las Cañadas Caldera (see Figure 4) (Vieira et al., 1986; Sevilla et al., 1986; Sevilla and Martín, 1986). It was observed several times between 1982 and 2000 to try to detect possible crustal displacements associated with volcanic reactivation within the network, and as a procedure for solving structural problems (Vieira et al., 1986; Sevilla and Martín, 1986; Sevilla and Sánchez, 1996). The network is located in the southern part of the Caldera and was 
observed using triangulation and trilateration. In addition, in 1994 a levelling profile was

connected to the geodetic network (Sevilla et al., 1996). It is composed of 52 levelling points, and was observed several times using precision trigonometric levelling. No significant displacements were found from 1982 to 2000 in the geodetic network or the levelling profile (Sevilla and Romero, 1991; Sevilla and Sánchez, 1996; Fernández et al., 2003).

A sensitivity analysis of these networks revealed important limitations for volcano monitoring, the most important being the small spatial aperture (Yu et al., 2000). The lack of any external control point outside of Las Cañadas Caldera prevented checking for relative displacements. The use of observational methodologies, with a precision of around $1 \mathrm{~cm}$ for detecting displacements between the dates of the different surveys, made it very difficult or quite impossible to detect any relative displacements inside the caldera which were below that value.

Lanzarote Island: The island's structural and geodynamic characteristics, together with the possibility of future activity, prompted the Instituto de Astronomía y Geodesia (IAG), in collaboration with the Lanzarote Inter-Island Council, to install a permanent Geodynamic Laboratory on Lanzarote in 1987 (Vieira et al. 1988, 1991a; Fernández, 1993; Fernández et al. 1993; Vieira 1994). The Laboratory's scientific tasks were Earth and oceanic tidal research and geodynamic research of volcanism and associated seismicity (Romero et al., 2003). Four different modules, three located in Cueva de los Verdes (inside the La Corona volcano lava tube) and the other in Timanfaya National Park, form the Lanzarote Geodynamic Laboratory (Figure 5). Several instruments were set up in this station since 1987 to permit the continuous observation of deformation, gravity changes, sea level, rock temperatures and different meteorological parameters (see the references in this section for more details). These modules were connected to a data centre located in the Casa de los Volcanes, and from it data were transferred via modem to Madrid. 
Most research in the last decades of the $20^{\text {th }}$ century in the Laboratory was done in the

field of Earth and oceanic tides (see e.g., Vieira et al., 1991b; Fernández et al., 1991; Fernández et al., 1992; del Rey et al., 1994; Vieira et al., 1995; Arnoso et al., 1998; Arnoso et al., 2000). However, some research also focused on studying how to apply the geodetic observation carried out in the Laboratory to volcano monitoring, developing theoretical models for interpreting geodetic observations and designgeodetic monitoring systems (see next sub-sections) (Fernández 1991; Fernández and Vieira, 1991; Fernández, 1993; Fernández et al., 1993; Fernández and Rundle, 1994; Fernández et al., 1994; Fernández and Díez, 1995; Fernández et al., 1999)

All data gathered show that no deformation or gravity change related to volcanic activity was detected between 1987 and 2000 (Fernandez et al. 1992; Fernández, 1993; Arnoso et al. 2000, 2001a, 2001b; Fernández et al., 2003).

Until the end of the year 2000 (Romero et al., 2003), the geodetic instruments installed on Lanzarote capable of providing information useful for volcano monitoring purposes only supplied information from two specific areas (Figure 5). The lack of information about the deformation field of the whole island causes two monitoring problems (pointed out by Fernandez 1993; Fernandez and Rundle 1994a; Fernandez et al. 1999): (a) difficulty to deduce information about the characteristics of the intrusion in case of volcanic unrest; (b) difficulty to identify a process of volcanic reactivation on the island. Moreover, this situation made it extremely difficult to study the time evolution of the volcanic source, an essential factor for making Civil Protection-related decisions. It should be stressed that possible future eruption scenarios in Lanzarote are not limited to a specific volcano, but to an extensive active volcanic region that covers nearly the whole island (Fernández et al., 2003).

La Palma Island: La Palma accounts for most of the eruptions that have occurred in the archipelago over the last 500 years (historic eruptions), and all the events in this island have taken 
place at the Cumbre Vieja ridge, to the south of the island (Romero, 2000). Indeed, the last sub-

aerial eruption in the Canary Islands occurred at Teneguía volcano in 1971, which is why La Palma has become one of the most closely monitored islands of the Canaries in recent decades (Perlock et al., 2008; González et al., 2010b).

In 2000 and 2001, this island became very famous among scientists and general society due to the publication of several articles (Moss et al., 1999; Day et al., 1999; Ward and Day, 2001), and the consequent appearance in the media of related news, which warned that a giant collapse affecting the western flank of the southern part of the island would generate a tsunami that could affect coastal areas around the North and Central Atlantic basin, although not all scientific researchers agree with this (e.g., Carracedo et al., 2009).

To assess the level of stability of the western flank of Cumbre Vieja (Moss et al., 1999), in the mid-1990s a geodetic network was installed and was used three times between 1994-1997 utilizing Electronic Distance Measurement techniques (EDM) and Rapid-Static GPS . However, these studies were limited in their spatial extension and temporal coverage. Although the results showed a coherent pattern of displacement vectors they were of the same order of magnitude as the associated errors (Perlock et al., 2008; González et al, 2010b) and therefore they could not be really significative.

\subsection{Deformation modeling and designing of the geodetic volcano monitoring.}

One of the main tasks facing volcanologists studying an active volcano area is to define the most suitable instrumental monitoring system, a task that is particularly difficult in the absence of recent activity (Fernández et al., 1999; Yu et al., 2000). This is the case for most active volcanoes that have not erupted for decades or even longer. This task not only involves the technical optimization of the monitoring systems but also their economic and scientific 
profitability (Fernández et al., 1999). In the 80s, the geodetic volcano monitoring situation was as

follows: (1) Several geodetic research programs were being carried out in Lanzarote and Tenerife by Spanish research teams including volcano monitoring purposes, with a limited yet constant economic cost. (2) The volcano geodetic research in La Palma was being carried out by UK groups. (3) There was a lack of knowledge of the magnitude and pattern of deformation and gravity variations expected in case of volcanic reactivation on any of the islands based on previous observational experience (Fernández, 1993). (4) There was a need to develop theoretical models and inversion techniques for monitoring use and interpretation in case of volcanic crisis (Fernández, 1993). (5) It was necessary to evaluate the applicability and limitations of the geodetic techniques and methodologies which were being applied to volcano monitoring. (6) It was necessary also to design the geodetic monitoring system for volcanic activity on each island and the entire archipelago.

In the frame of the existing international tendency (Baldi and Unguendoli, 1987; Johnson and Wyatt, 1994; Dvorak and Dzurisin, 1997; Harris et al., 1997; Segall and Mathews, 1997; Betti et al., 1999; Wu and Chen, 1999) it was decided to use theoretical models, developing new ones, as well as new inversion techniques (Yu et al., 1998, Tiampo et al., 2000), and to use them together with observational experience and results and knowledge about the crustal structure, to define the most suitable geodetic volcano monitoring system from a theoretical study of sensitivity to ground deformation and gravity changes (Fernández et al., 1999). It was done that way considering aspect (3) described above, but also always bearing in mind that no theoretical study can consider all the variables involved in a problem. Therefore, the results obtained would only approximate reality but could give us a useful idea of how to design geodetic observation for the purposes of monitoring volcanic unrest.

Fernández (1993), Díez-Gil et al. (1994), Fernández and Rundle (1994a) and Fernández and Díez (1995) dealt with the issue of defining the most suitable geodetic monitoring system by 
studying Lanzarote, the easternmost of the Canary Islands, and the southern area of the island of the methodology to the Teide, the stratovolcano in Tenerife. They propose a volcano geodetic monitoring system which uses the existing facilities on each Island complemented with continuous observation or deformation and gravity networks, depending on each case. Continuous recording instruments, based on their high sensitivity, should serve as a primary tool to detect precursory geodetic signals and field observation should be used to solve the inverse problem and determine intrusion characteristics.

On account of the two main limitations of the work described by Fernández et al. (1999), namely the kind of source considered (spherical point magma intrusion) and the limitation in size of the zone studied, Yu et al. (2000) extended it to consider a wider zone and probably a more realistic source for Tenerife Island considering its eruption history, a dike. Their study leads to the conclusion that the existing geodetic network on Tenerife island is capable of detecting dike intrusions just below the area covered by the network, and when they are very close to the surface. GPS observations, using continuous recording stations or a very short period of reobservation, covering the whole surface of the Island, would be required to detect the effects caused by the temporary rise of an intrusion towards the surface.

\subsection{New techniques.}

By the end of the $20^{\text {th }}$ century, theoretical studies had shown a clear limitation of the observational system deployed in the islands and the need to cover the entire surface of the Islands to perform operative geodetic volcano monitoring. This could not be done using classical geodetic techniques due to their characteristics and the economic and time costs of thoset observations (Fernández at al., 1999; Yu et al., 2000; Dzurisin, 2007). Yet the observational 
situation changed dramatically in the late $20^{\text {th }}$ century due to two events of great scientific and

technical relief. The first, the widespread use of GNSS observation to study deformations (e.g., Dong and Bock, 1989; Bock, 1991; Dixon et al., 1997; Fernández et al., 1999; Sagiya et al, 2000; Dzurisin, 2007) caused by the advance of technology that allows improved accuracies and cheaper, much smaller geodetic GPS receivers, linked to permanent GNSS observation.

The second event was the appearance, with a rapid development and expansion of its use, of Synthetic Aperture Radar Interferometry (InSAR) (Massonnet and Feigl 1998, Bürgmann et al., 2000; Hanssen 2001) which, in good conditions (Fernández et al., 2005) allowed areas of 100 x $100 \mathrm{~km}^{2}$ to be covered in a single image, i.e. covering complete Islands (Carrasco et al., 2000a; Fernández et al., 2002), with high spatial resolution and, in after a few years, precision (Fernández et al., 2009; González and Fernández, 2011). Both events drastically changed, the geodetic monitoring of volcanic activity worldwide and in particular for the Canary Islands. Both techniques are currently validated and evolved, are currently used in detecting ground movements and have brought down costs compared with classical geodetic techniques (Fernández et al., 2003).

A clear example of the impact of using these techniques in the Canary Islands can be seen in Tenerife Island, described below (see, for more details, Carrasco et al., 2000a, b; Fernández et al., 2002; Rodríguez-Velasco et al., 2002; Fernández et al., 2003, 2004, 2005).

InSAR application and results: In the first InSAR study of Tenerife Island, 18 radar images acquired by the European Space Agency satellites ERS-1, 2 during the period 1992-2000 were used, obtaining 21 differential interferograms. The good coherence obtained, even for time-spans beyond 7 years, permitted three important results: (a) InSAR could be applied on Tenerife for routine monitoring; (b) No deformation at Las Cañadas caldera (see Figure 6) was detected for that period (which was in agreement with the results described previously and obtained using 
classical geodetic techniques); and (c) the detection of two deformation zones outside usually

observed areas, located in the region where the most recent eruptions in the island occurred (Montaña Negra 1706, Chahorra 1798, Chinyero 1909): Garachico and Chío deformations areas (see Figure 6). Both of them were subsidences, increasing from 1992 to 2000. By way of example, Figure 6 displays the location of these deformations and their magnitudes from 1993 to 2000.

GPS network: definition and first observation results. Previously described results prompted researchers to design and observe a GPS network covering all Tenerife in 2000. The main objectives were the geodetic monitoring of possible displacements associated with volcanic reactivation and corroborating the results obtained by InSAR. This GPS network has a station in the deformation zone (2) (see Figure 6) and a densification in the deformation zone (1) (Figure 6) located to the south of the village of Garachico (see Figure 7). For details of the observation and processing methodologies, see Rodríguez-Velasco et al. (2002), Fernández et al. (2003 and 2004). The precision of the obtained results is within one centimeter in height and several millimeters in horizontal coordinates. Results (Figure 8) showed a subsidence of station Pinar de Chío, of the same order as obtained using InSAR in deformation zone (2), and thherefore the two techniques confirmed one another. The results obtained in the deformation zone (1), to the south of the town of Garachico, were not definitive enough to confirm the displacements detected using InSAR.

\section{Recent studies.}

The other major change in the Canaries, which has driven the development of research in volcanic activity monitoring in the archipelago, has been the significant increase in activity 
coinciding with the beginning of the $21^{\text {st }}$ century. This is reflected in the seismic-volcanic crisis

of Tenerife (2004-2007) that concluded without an eruption, and the underwater volcanic eruption on the island of El Hierro (2011-2012), which has been followed by various episodes of significant surface deformation and seismic activity in 2012 and 2013 (http://www.ign.es/ign/resources/volcanologia/HIERRO.html; García et al., 2014). This has forced the use and development of new techniques for the improvement and optimization of geodetic monitoring, in both observational and theoretical (interpretation tools) aspects, as well as for the knowledge of the crustal structure of the different Islands. The last is a basic aspect for a correct discussion and interpretation of any observed anomaly during unrest episodes (see e.g., Gottsmann et al., 2008).

Sensors and techniques developed in recent years in the different fields of geodesy (GNSS, Earth observation from space, gravimetry,...) have allowed both ground deformation and gravity variations that occur before, during and after events volcanic to be measured with a precision, spatial and temporal coverage unimaginable a few decades ago (Fernández et al., 1999; Sigurdsson et al 2000; Gottsmann et al., 2006; Dzurisin, 2007; Battaglia et al., 2008, Crossley et al., 2013). These innovative observational techniques have entailed developing new methods of data processing and interpretation (theoretical models and inversion techniques), allowing rigorous and objective information to be obtained from these new observations.

\subsection{Structural studies.}

In the 21 st century, several gravimetric works (sometimes complemented with microseismic experiments) have sought to better define gravity anomalies and show structural details on different islands such as Lanzarote (Camacho et al, 2001; Gorbatikov et al, 2004), Tenerife (Chávez-García et al, 2007; Gottsmann et al, 2008; Camacho et al, 2011a, b), 
Fuerteventura (Montesinos et al, 2005), La Palma (Camacho et al, 2009), El Hierro (Montesinos

et al, 2006; Gorbatikov et al, 2013), and La Gomera (Montesinos et al, 2011.), and in the vicinity of the Canary Islands (Llanes, 2006).

In almost all on-shore studies for the different islands, the structural pattern is similar. The oldest volcanic zones have strong positive gravity anomalies, which are interpreted in terms of large magmatic intrusive bodies and aggregation of dikes corresponding to phases of very massive shield volcanism. The areas of most recent volcanic activity (and therefore potentially more active) are characterized by negative gravity anomalies, which are partly due to fracturing and slight accumulation of unconsolidated volcanic material which still being not eroded. Some of these works allow different authors to relate the determined crustal structures with displacement or other anomalies detected during the recent volcanic crisis in the archipelago (Gottsmann et al, 2008; Gorbatikov et al, 2013.).

For example, in the case of Tenerife a large body of high density is located slightly to the SW of the center of the island (see Figure 3), which is associated with very consolidated magmatic intrusions. Other areas of positive anomaly (high density) can be associated with ancient structures and massive rift volcanism. In the center of the island, a strong significant minimum is identified revealing the low density of materials accumulated forming the Teide and the filling of the volcanic caldera. The morphology of these low density elements leads Gottsmann et al (2008) to ensure they support a vertical collapse origin of the caldera, and map the headwall of the ca. 180 ka Icod landslide, which appears to lie buried under the Pico ViejoPico Teide stratovolcano complex.

For the other islands, models and conclusions are similar, and each successive study improves the morphological definition of the structures. For example, for La Palma the following characteristics can be described (Camacho et al., 2009): a large body of high density in the northern half corresponding to ancient volcanism massive; a high-density structure elongated 
along the NS rift in the middle; and lower densities in the south and on both sides of the central

rift, associated to fracturing, to light recent volcanic deposits and zones of very recent activity (as Teneguia volcano at the south end of the Island).

\subsection{Measurement of deformation and gravity changes.}

Tenerife Island: The first results from applying InSAR to Tenerife Island are described by Carrasco et al. (2000a, b), Romero et al. (2002) and Fernández et al. (2002, 2003, 2005) and they were shocking, even using classical DInSAR technique and a reduced number of radar images (see previous section), because they showed clear deformation areas (Figure 6) in areas not studied before. These results further emphasized the need to define a GPS network covering the whole island (Figure 7), which was defined and formed (Fernández et al., 2003, Fernández et al., 2004) by 17 vertices from the existing network, with accurate coordinates determined by the REGCAN-95 geodetic system (Caturla 1996) plus the permanent station at Santa Cruz de Tenerife (TENE; Fernández et al. 2003). Beginning in 2000, GPS observations confirmed the DInSAR detected subsidences and the time variability of the displacement, and also showed that the horizontal component displacement was very unimportant compared with the vertical one (Fernández et al., 2003; 2004; 2005). These localized subsidences were attributed primarily, at least partially, to changes in the groundwater level (Fernández et al., 2005). Results for elevation change, comparing coordinates determined for each campaign, are shown in Figure 8.

Background seismicity in the Canary Islands, at least during the last decades of the $20^{\text {th }}$ century, was characterized by diffuse and disperse seismicity in most of the region, concentrated in an area located between the island of Tenerife and Gran Canaria as well as in a NW-SE line, where there is submarine alignment of volcanic seamounts (Romero Ruiz et al., 2000). 
Anomalous low-magnitude seismicity was recorded in and around Tenerife island from

2001 by the National Geographic Institute of Spain (IGN) network (IGN, 2006), but more significantly during 2004 and 2005, close to a century after the last eruption in the island. A combined analysis of the observed geochemical and seismic data prior the recent seismic swarm on 2004 suggested that subsurface magma movement could be the potential mechanism for this observed seismic activity increase (Pérez and Hernández, 2004; Pérez et al., 2005). This 20042005 anomalous seismic activity has been characterized by having a great number of epicenters located inland of Tenerife island and some migration with time, Figure 9, as in other volcanic areas (e.g., Waite et al., 2002; Wicks et al., 2006). From April to December 2004, 195 seismic events were located, five of them felt in May, July and August 2004; and more than 350 seismic events to February 2006. The total number of recorded seismic events during the same period, including those not located, exceeded 3,000. The model proposed by Almendros et al. (2007) to explain the pattern of seismicity observed includes an initial deep magma intrusion under the northwest flank of Teide volcano, and the associated stress changes produced the deep volcanotectonic cluster. In turn, the occurrence of earthquakes permitted and enhanced the supply of fresh magmatic gases toward the surface. The gases permeated the volcanic edifice, producing lubrication of pre-existing fractures favoring the occurrence of volcano-tectonic earthquakes. On 18 May, the flow front reached the shallow aquifer located under Las Cañadas Caldera, and the induced instability was the driving mechanism for the observed tremor.

This reactivation produced surface gravity changes (Gottsmann et al., 2006) indicating that the activity was accompanied by a sub-surface mass addition, although no widespread deformation was detected initially. While magma recharge at depth into the northwestern rift zone of Tenerife is likely to have triggered the reawakening of the central volcanic complex, the cause of the 14-month perturbation of the gravity field is most probably not related to magma 
flow. A more likely scenario is the migration of fluids inside the complex triggering the observed gravity changes.

Some deformation at surface has been detected, associated to this reactivation, using GNSS (see Figure 8) and InSAR (see Figure 10) observations and described in different works (González et al., 2005; Prieto et al., 2005; Fernández et al., 2006, 2007; 2008; Samsonov et al., 2008; Fernández et al., 2009; González et al., 2010a; Tizzani et al., 2010).

Samsonov et al. (2008) present results for the three-dimensional displacement field on Tenerife Island calculated from GPS campaigns and ascending and descending ENVISAT DInSAR interferograms. The goal of their work is to provide an example of the flexibility of the technique by fusing together new varieties of geodetic data, and to observe surface deformations and study precursors of potential activity in volcanic regions. Interferometric processing of ENVISAT data was performed with GAMMA software. All possible combinations were used to create interferograms and then stacking was used to increase signal-to-noise ratio. Decorrelated areas were widely observed, particularly for interferograms with large perpendicular baseline and large time span. Tropospheric signal was also observed, which significantly complicated the interpretation. Subsidence signal was observed in the NW part of the island and around Mount Teide and agreed in some regions with GPS campaign data.

Fernández et al. (2009) study the state of deformation of Tenerife (Canary Islands) using Advance Differential Synthetic Aperture Radar Interferometry (A-DInSAR). They apply the Small BAseline Subset (SBAS) (Berardino et al., 2002) DInSAR algorithm to 55 radar images acquired from descending orbits (Track 352, Frame 3037) by the ERS-1/2 satellites during 1992 2005. Their analysis reveals, Figure 10, that the summit area of the volcanic edifice is characterized by a rather continuous subsidence extending well beyond Las Cañadas caldera rim and corresponding to the dense core of the island. These results were undetectable using classical DInSAR or any GPS network formed by isolated stations and observed on a survey basis. These 
results, coupled with GPS ones, structural and geological information and deformation modeling, suggest an interpretation based on the gravitational sinking of the dense core of the island into a weak lithosphere and that the volcanic edifice is in a state of compression. Fernández et al. (2009) also detect more localized deformation patterns, some of them previously detected using classical DInSAR (see Figures 6 and 10). They were also able to determine deformation time series for the coherent pixels, see Figure 10, and it is easy to see variations in the deformation time series associated with the seismic crisis in 2004.

Apart from the previously described short-term surface deformation, characterized by a broad subsidence pattern with maximum ground velocities of about $4 \mathrm{~mm} / \mathrm{yr}$ detected via spacebased geodetic observations (Fernández et al., 2009), different geophysical researchs (Watts, 1994; Watts et al., 1997; Watts and Zhong, 2000; Collier and Watts, 2001; Minshull and Charvis, 2001) have identified that the Tenerife volcanic complex is affected by crustal deformation processes occurring on timescales of millions of years. With the purpose of studying the relationship between these long-term and short-term deformation processes, Tizzani et al. (2010) performed an advanced fluid dynamic analysis (FDA). Their results interpreted the recent surface deformation as mainly caused by a progressive sagging of the denser (less viscous) core of the island onto the weaker (but more viscous) lithosphere. Moreover, over periods comparable to the hypothesized age of loading of the oceanic crust beneath Tenerife, this tendency would result in a total flexure of about 3-4 km, which is in agreement with independent estimations based on geophysical analyses. They use a unitary physical model to explain both the deformation recorded in deep geological structures and the current active ground deformation processes occurring at the Tenerife volcano.

A more recent GPS and SBAS-DInSAR data combination was performed for Tenerife Island (González et al., 2010a). In this study, the same GPS dataset were correlated for inner consistency against some previous SBAS-DInSAR results (Fernández et al., 2009). Some 
agreements and disagreements were found among the different regions covered by both datasets.

Significant positive correlation was obtained for the NW rift zone, indeed it was expect because GPS surveys are denser in space and time in this part of the Island.

Considering some of the previous results, the related volcanic hazard and potential risk at Tenerife as well as the recent anomalous seismic activity from April 2004, a permanent GPS network of 7 stations on Tenerife was installed by scientists from ITER, the Institute of Astronomy and Geodesy (IAG), the Research Center for Seismology, Volcanology, and Disaster Mitigation of the Nagoya University, Japan, and the Technological University of Madrid (UPM) (González et al., 2005; Prieto et al., 2005; Fernández et al., 2006). The spatial distribution can be seen in Figure 11. The network sought to provide the best possible coverage of the Teide volcanic cone, deformation areas found by InSAR in that epoch (Fernández et al., 2005) and a preestimated non deformation area located at the south part of the island, at the ITER facilities.

First results were obtained using Bernese 4.2 (Hugentobler et al., 2001; Fernández et al., 2006) for the period June 2004-January 2006 (Figure 11) showing a significant positive elevation changes for TEIT (4.4 mm/yr) and PORT $(9.5 \mathrm{~mm} / \mathrm{yr})$ and LANO $(-2.4 \mathrm{~mm} / \mathrm{yr})$ in the western sector of the network. Conversely a subsidence effect is observed in the north-east station LANO $(-1.9 \mathrm{~mm} / \mathrm{yr})$. On the other hand, significant EW displacements are observed in the eastern half of the network.

Taking into account that seismic activity has been one of the main indicators of geological unrest in Tenerife, correlation between GPS results and seismic activity was tried as a primary search for the GPS information. Some significant correlations were detected for stations PORT $(\mathrm{R}=-0.31)$ and NORD $(\mathrm{R}=0.28)$. Both stations and components present trends $(9.5 \mathrm{~mm} / \mathrm{yr}$ for PORT-U and $-1.86 \pm 0.37 \mathrm{~mm} / \mathrm{yr}$ for NORD-E) and correlation $(\mathrm{R}=-0.33)$ between them. This suggests that the area close to these stations (mainly $\mathrm{N}-\mathrm{W}$ of Teide) could have some deformations related with the seismicity (Fernández et al., 2006). 
In an unrelated way from the previously described GNSS networks, another one, the

TEGETEIDE network, was set up in 2005 and re-observed each year (Berrocoso et al., 2010). It is composed of seven GNSS-GPS stations scattered throughout the island. They presented, based only on the variation in these 7 stations' coordinates, a horizontal deformation model for the whole surface of the island in order to explain the observed island displacement pattern in the geodynamic context of the Nubian plate. They concluded that the most important geologic structures, such as the volcanic rifts and the caldera, determine the current deformation pattern of Tenerife. The geodynamics of the most stable areas of the island behave similarly to that observed from the permanent GNSS-GPS reference stations located in La Palma and Gran Canaria Islands. They present an anomalous geodynamic behaviour detected in two zones of Tenerife, which configure an NW-SE axis crossing the central sector of the island, related with the volcanotectonic activity of the island and its surroundings.

The Island of Tenerife is also home to a world-class astronomical observatory, the El Teide Observatory, where four tiltmeters, two aligned in the North-South direction and the other two in the East-West direction, are monitoring the movements of the solar telescope THEMIS (Heliographic Telescope for the Study of Solar Magnetism and Instabilites). Considering THEMIS is located a few kilometers from the El Teide-Pico Viejo stratovolcano, and the precision of the inclinometers is comparable to those used in geophysical studies, Eff-Darwich et al. (2008) carried out the analysis of the tilt measurements for the period 1997-2006. The THEMIS tiltmeters are located on the seventh floor of a tower, and hence they are less sensitive to geological processes than geophysical installations. However, THEMIS measurements are the only terrestrial data available in Tenerife for such a long period of observations, which include the sustained increase in seismic activity that started in 2001. They found a significant change in the East-West tilt of approximately $35 \mu$-radians between the years 2000 and 2002. Some theoretical models were calculated and it was concluded that such tilt variation could not be due 
to dike intrusions, nor a volcanic reactivation below the El Teide-Pico Viejo volcano. The most

likely explanation (Eff-Darwich et al., 2008) comes from dislocations produced by a secondary fault associated to a major submarine fault off the eastern coast of Tenerife. They also conclude that, taking into account the nearly permanent data recording at THEMIS, the clinometers could be considered as a complement for any ground deformation monitoring system in the island.

During and after the 2004 volcano-tectonic crisis, the Instituto Geográfico Nacional (IGN), which is officially responsible for volcano monitoring in Spain, has developed and deployed a geodetic volcano monitoring system based on classical geodesy such as precision leveling and measuring electromagnetic distances and space techniques, especially GPS. A permanent network has been designed with continuous data logging and acquisition in real-time. It consists of permanent GPS stations and tide gauges (http://www.fomento.gob.es/Contraste/MFOM/LANG_CASTELLANO/

DIRECCIONES_GENERALES/INSTITUTO_GEOGRAFICO/Geofisica/volcanologia/B70_geo desia.htm).

The Advanced DInSAR (A-DInSAR) CPT technique (Mallorquí et al., 2003; BlancoSánchez et al., 2008) has been also applied to study surface deformation in Tenerife. Arjona et al. (2009) studied two set of ESA radar images, a set of ENVISAT ascending images for 2003-2008 period and a set of ENVISAT descending images for the period 2004-2008. Their results are consistent with the ones obtained by Fernández et al. (2009). They did not carry out any interpretation of the detected displacements or conduct any detailed study in connection with the volcano-tectonic crisis.

Many of the previous works, mainly in relation with the 2004 volcano-tectonic crisis, present clear limitations. Not a single study covers from 1992 to any time after the end of the crisis (about 2006). There are no detailed studies of the advanced DInSAR deformation time 
series before, during and after the crisis, including an interpretation, or a GPS and DInSAR data combined analysis covering the entire crisis period.

Lanzarote Island: During the first decade of this century, the Lanzarote Geodynamics facilities are being used to carry out many Earth tide works, sometimes looking for a possible application of the tidal observations for volcano monitoring but without any clear result in this aspect or in the detection of displacements or gravity changes (see e.g., Kalinina et al., 2004; Arnoso et al., 2001a, b, c; Venedikov et al., 2006; Arnoso et al., 2011). GNSS observations have also carried out, serving to support the tide gauges installed in the laboratory (García-Cañada and Sevilla, 2006) and using a single permanent GNSS-GPS station.

The lack of geodetic monitoring networks covering the whole Lanzarote Island motivated the use and testing of applicability of classical DInSAR for monitoring volcanic deformation on the Island (Romero et al., 2003). They used six radar images acquired by the ERS-1 and ERS-2 satellites during the period 1992-2000. The analysis of these images confirmed the existence of long-term stability coherence across most of the island due to dry climate conditions and the large extension of recent lava flows. The analysis of 15 (redundant) interferograms allowed them to distinguish relatively important atmospheric contributions in the differential interferograms on Lanzarote, and to conclude that there has been no displacement greater than $3 \mathrm{~cm}$ on the island during the period studied. These results show a clear need for a multitemporal analysis of interferometric products and the assessment of errors to look for possible small displacements below the $3 \mathrm{~cm}$ level.

González and Fernández (2011) applied a new error estimation multitemporal method on Lanzarote Island. They used a set of 14 SAR scenes from the European Space Agency (ESA) of satellites ERS-1 and ERS-2, descending orbit, acquired in the period 1992-2000. See González and Fernández (2011) for details about the InSAR processing. Their results are shown in Figure 
12. Figure 12a shows the map of the linear velocity map from the estimated time series of displacements for each coherent pixel in mm/year. In addition, the mean square root of the residuals with respect to the linear model for all times series is of the order of $\sim \pm 1 \mathrm{~mm} /$ year. Most of the area of Lanzarote (and northern islets) is stable at the level of $\sim \pm 1 \mathrm{~mm} /$ year during the studied period. Two areas (central part and northwestern coast) show significant lengthening displacement rates (most likely a subsidence signal). The largest deformation rates are associated to the Timanfaya eruption area (Montañas del Fuego) with linear velocities of 4-6 mm/year, and affecting an area of about $7 \mathrm{~km}^{2}$. The second deformation area is smaller in magnitude (3-4 $\mathrm{mm} / \mathrm{year}$ ) and located on the northwestern coast. Despite the low magnitude of the deformation rate measured along the points between both deformation areas, points indicate systematic positive (subsidence) deformation rates. It could indicate spatial continuity and a possible connection between both areas (and the generating sources). Figure 12a shows also the location of some selected time series. Time series (Figure 12b-12e) represent the estimated displacement evolution and associated estimated error (displayed as 2-sigma error bars) for 8 coherent pixels.

The time series illustrate that the estimated errors are in the range of 5-8 $\mathrm{mm}$, although the repeatability is slightly higher $(\sim 1 \mathrm{~cm})$. This observation is in accordance with previous results about the reliability of SB techniques (Casu et al., 2006). Deformation closely follows the surface temperature anomalies indicating (González and Fernández, 2011) that magma crystallization (cooling and contraction) of the 300-year shallow magmatic body under Timanfaya volcano is still ongoing. Unfortunately, no independent ground deformation estimates were available for comparison, even considering the proximity of deformation areas to Timanfaya module of the Lanzarote Geodynamics Laboratory.

La Palma Island: The tsunami caused by the earthquake in SW Asia on $26^{\text {th }}$ December 2004, which cost an enormous amount both in human lives and economic terms, spotlighted the 
catastrophic works published on the likelihood and possible effects of a landslide on the Island of interesting to determine if there are any displacements on the island that might be associated with possible landslides (González et al., 2010b).

InSAR results obtained using images from 1992 to 2000 acquired by ERS-1 and 2 ESA satellites and using three different InSAR phase analysis techniques (Coherent Pixel Time Series technique, Coherent Target Modeling Method, and Stacking) show a clear subsidence located on the Teneguía volcano where the last eruption on La Palma took place in 1971. Stacking technique also shows a mild long wavelength signal of subsidence in the western part of Cumbre Vieja. The linear velocities of subsidence are between 4 and $9 \mathrm{~mm} / \mathrm{year}$. No deformation, at the measured level of precision, along the coherent pixels in the northern part of the island has been detected (Perlock et al., 2008).

Fernández et al. (2008) and Prieto et al. (2009) projected and surveyed a GPS network covering La Palma Island using geodetic infrastructure installed by the Instituto Geográfico Nacional in the 1990's. This network includes control stations along the Cumbre Vieja rift and its flank, Cumbre Nueva slope, also inside and outside Taburiente Caldera and two stations at Teneguia volcano, Figure 13. The geodetic network was observed in 2006, 2007 and 2008. The same equipment and observation methodology was used for all campaigns. See Fernández et al. (2008) and Prieto et al. (2009) for details about the observation and data processing.

A widespread subsidence was observed (Figure 13b) (Prieto et al., 2009), more emphasized in the western flank of the island and which varies from about $7 \mathrm{~cm}$ in the north up to approximately $4 \mathrm{~cm}$ in the south, with standard deviations of about $1 \mathrm{~cm}$. The effect is smaller in the east flank. Therefore, in the south, they obtain a velocity of subsidence close to $4 \mathrm{~mm} /$ year, consistent with results previously obtained using DInSAR (Perlock et al., 2008). Horizontal 1994-2007 displacements are shown in Figure 13a showing for the western flank a $2 \mathrm{~cm}$ 
displacement to the south with formal errors for all those markers under the $7 \mathrm{~mm}$ level. Between 2006 and 2007 (Figures 13d) a subsidence of the western flank still remains, but some points do not agree. The Caldera de Taburiente and its water-course to the sea describe a movement in the opposite direction. The northeast part of the island, with no markers on the previous study, also describes a displacement in the same direction as for the caldera. Displacements on the southeast flank are minor, following the same trend as seen for the 1994-2007 period. Displacements vectors in Cumbre Vieja seem to follow an erratic trend, being of the same magnitude as their formal errors. There are no significant displacements detected in that area. Markers on the south of the island, close to or in the area where the last eruption of the Teneguia volcano occurred, follow the same subsidence as the western flank. Therefore the tendency is consistent with DInSAR results again. For the 2006-2007 period (Figure 13c), stations located on the western flank show southward displacement, but with only a 6month interval, and their magnitudes are similar to their standard deviations. The points on the caldera surroundings fit displacements in a northwest direction, as do the markers placed on the east flank. Some points on the western flank of Cumbre Vieja show eastward displacements together with the majority of the points at its south end.

All the observed significant displacements affect stations located outside the large central high density body obtained by the inverse gravimetric approach (Camacho et al., 2009). Therefore, detected displacements are located in younger areas and with more recent activity.

Arjona et al. (2010) processed a stack of 15 ascending images from the period 2004-2007, a second set formed by 18 descending covering 2006 up to 2008, and a final data set formed by 16 descending images covering 1992 up to 2000 from ERS sensor using CPT A-DInSAR technique. Their results were consistent with results described by Prieto et al. (2009). No interpretation work was done in this study. 
González et al. (2010b) analyzed 25 SAR images acquired by the European Remote Sensing (ERS1/2) satellites between May 1992 and September 2000 and 19 ASAR images acquired by the ENVISAT satellite from March 2003 to February 2008, archived by the European Space Agency (ESA). They selected descending SAR images, roughly sampled regularly over the period studied (1992-2008), to obtain a detailed image map of the ground deformation at Cumbre Vieja volcano. A similar analysis using ascending data was not feasible due to severe foreshortening that would result from the steep slopes of the western flank of Cumbre Vieja. See González et al. (2010b) for details on InSAR processing and atmospheric effect mitigation. They concentrated their ground deformation analysis in the active rift zone of Cumbre Vieja using average LOS velocity maps from the 1992-2000 (Figure 14a) and 20032008 (Figure 14b) periods. Their results show two clear subsidence signals at the Teneguia volcano area and on the western slopes of the Cumbre Vieja volcano (Figure 14). The detected deformations were calculated using the descending orbit pass, so it could be either subsidence, westward motion or a combination of the two. The results by Prieto et al. (2009) suggest that a large part of the ground motion could be vertical.

González et al. (2010b) modelled the ground deformation using a rectangular dislocation with free dip-slip motion on the fault plane, simulating in a homogeneous, isotropic and elastic half-space a normal fault mechanism (Okada, 1985). Creeping processes with associated nonvolcanic tremor may release the stress on the sliding surfaces, a process that potentially can remain undiscovered without dedicated seismic observations. The smoothness and spatial distribution of our geodetic results (Figure 14) suggests that the detachment fault is slow stablesliding at depth beneath the western flank of the edifice in the on- and offshore region close to the shoreline, on a fault segment with creeping friction properties. This behaviour is likely steadystate, or might be punctuated by unobserved slow-slip events, in the transition zone between 
frictionally different segments of the developing fault surfaces (Brooks et al., 2006; Segall et al., 2006). Only during eruptions, the slip assumption of homogeneity can be accepted.

Elastic modelling of the radar data could explain observed deformation with slip on an active creeping detachment surface that fits the contour of the low density zone. Spatial coalescence of (a) a prominent volcano edifice underlain by a ductile layer (old sediments or debris avalanche deposits), (b) a buried buttress structure in the eastern flank and (c) concentrated westwards dilatational magmatic stresses due to repeated $\mathrm{N}-\mathrm{S}$ rift intrusions in the last $7 \mathrm{ka}$ results in the initiation and progressive development of an active aseismic mobilisation of the western flank. They concluded that the detachment layer may act as an efficient boundary for the aseismic stress release due to gravitational loading during intereruptive periods (present activity), encouraging dike intrusions at the $\mathrm{N}-\mathrm{S}$ rift zone. The release of dilatational magmatic stresses during these N-S rift intrusions encourages slip and promotes high-angle normal faulting at the border of the slip area (1949 eruption), reorienting the stress field around the volcano and resulting in near E-W fissural eruptions in the western flank. This simple model (González et al., 2010b) satisfactorily explains the ground deformation data and also complements the geological and geophysical evidence that Cumbre Vieja volcano is in an early state of an immature collapsing process $(<20-7 \mathrm{ka})$. They speculate that ongoing creeping beneath the western flank of Cumbre Vieja tends to stabilize the flank through reorganization and a decrease of gravitational potential forces. This conclusion does not preclude that any sudden and/or unusual change in the stress field, such as a dike intrusion or groundwater pressurization, could trigger a catastrophic collapse (González et al., 2010b).

El Hierro Island: Ground tilt and gravity measurements were carried out at stations on El Hierro Island from 2004 to 2010 . Tilt variation associated to seasonal temperature effects and after period of heavy rains, sometimes associated to landslides, were detected (Arnoso et al., 2008). 
Gravity tide records have been analyzed and compared to DDW theoretical body tide model

(Arnoso et al., 2011). No precursory deformation or gravity change for the 2011 volcanic crisis was published for those instruments.

Starting in July 2011, anomalous seismicity was observed at El Hierro Island. On $12^{\text {th }}$ October 2011, the process led to the beginning of a submarine NW-SE fissural eruption at $\sim 15$ $\mathrm{km}$ from the initial earthquake loci, indicative of significant lateral magma migration. A description of the different phases of activity during that time period can be seen in Carracedo et al. (2012), López et al. (2012), Ibañez et al. (2012), Martí et al. (2013) and González et al. (2013). Deformation and gravity changes were measured before, during and after the eruption (Lopéz et al., 2012; Arnoso et al., 2012; Sagiya et al., 2012; González et al., 2013; García et al., 2014).

López et al. (2012) describe the multiparametric monitoring network deployed over the El Hierro Island by the Instituto Geográfico Nacional (IGN) from July 2011 to the eruption onset on October 2011. They cover the recording of seismicity, geochemistry, geomagnetism, gravimetry, GNSS, InSAR and other additional measurements (e.g., temperature, $\mathrm{pH}$ and electric conductivity at wells). They do a description of the different parameters variations during the different phases of the pre-eruption time period. No data inversion for interpretation is carried out.

Prates et al. (2013) present a processing strategy to achieve millimeter-level half-hourly positioning solutions using GPS-GNSS data and describe deformation results for July-November 2011. Some interpretation using a Mogi point source is done. Months after the eruption a new deformation was measured, of greater magnitude than before the eruption.

Martí et al. (2013) combined geological, geophysical, geodetic, and petrological data and numerical modeling to propose a volcanological model of the causes and mechanisms of the El Hierro eruption. They conclude that the stress distribution in the crust beneath the Island, influenced by rheological contrast, tectonic stresses and gravitational loading, controlled the movement and eruption of magma. They do not carry out a geodetic data inversion for their 
interpretation, using a speculative modeling based on the available data. They consider seismicity, deformation and petrological data indicate that a bath of basanitic magma coming from around $25 \mathrm{~km}$ depth was emplaced at 10-12 km depth (discontinuity mantle/crust beneath El Hierro) creating a new reservoir where magma evolved until the initiation of the eruption. After about two months, magma migrates laterally toward SE for nearly $20 \mathrm{~km}$, always keeping the same depth and following a path controlled by stress barriers created by tectonic and rheological contrast in the upper lithosphere, ending with the submarine eruption.

González et al. (2013) complement the ground-based geodetic network with comprehensive processing, analysis, and modeling of multiple space-based radar interferometric data sets (RADARSAT-2, ASAR-ENVISAT, and COSMO-SkyMed (Constellation of Small Satellites for Mediterranean Basin Observation)) in order to understand the dynamics of the magmatic system, with a temporal sampling of $\sim 10$ days during the eruption. Their results demonstrate the applicability of radar observations to studying offshore eruptions, if occurring close to the coast. The data fully captures both the pre-eruptive and coeruptive phases. Elastic modeling of the ground deformation is employed to constrain the dynamics associated with the magmatic activity. This study represents the first geodetically constrained active magmatic plumbing system model for any of the Canary Islands volcanoes, and one of the few examples of submarine volcanic activity to date. Geodetic results reveal two spatially distinct shallow (crustal) magma reservoirs, a deeper central source $(9.5 \pm 4.0 \mathrm{~km})$, and a shallower magma reservoir at the flank of the southern rift $(4.5 \pm 2.0 \mathrm{~km})$ (see Figure 15). The deeper source was recharged, explaining the relatively long basaltic eruption, contributing to the observed island-wide uplift processes, and validating proposed active magma underplating. The shallowest source may be an incipient reservoir that facilitates fractional crystallization as observed on other Canary Islands. Data from this eruption supports a relationship between the depth of the shallow crustal magmatic systems and the long-term magma supply rate and oceanic lithospheric age. Such a relationship 
implies that a factor controlling the existence/depth of shallow (crustal) magmatic systems in oceanic island volcanoes is the lithosphere thermomechanical behavior.

Gorbatikov et al. (2013) identify in the structural model for El Hierro an intrusive model at $15-25 \mathrm{~km}$ depth, suggesting it could be associated with the submarine 2011-2012 eruption.

García et al. (2014) study seismic data and displacements determined using GPS-GNSS observations from 2011 to 2013. They suggest that several magma displacement processes occurred at depth from the beginning of the unrest in July 2011. The first one culminated with the submarine eruption (October 2011). For this process they obtain, from inversion, results consistent with the InSAR data inversion results by González et al. (2013). They also invert deformation data for the main processes of magma injection between August 2011 and April 2013, showing a stepwise magma migration process controlled by the distribution of the maximum differential stress induced by each of the new emplaced magma pressure sources.

Fuerteventura Island: A set of 23 SAR descending orbit radar images from ENVISAT satellite from the ESA archive, acquired in the period 2003-2010, were used for an A-DInSAR analysis. All scenes were co-registered to a common master geometry (October 12, 2006) and differential interferograms were computed using the DORIS software (Kampes et al., 2003). A 25-meter resolution DEM from the Gegraphical National Institute of Spain (IGN) was used to remove the topographical contribution. A spatial multilooking factor of $4 \times 20$ (rangexazimuth) was applied, producing pixel sizes of about $80 \times 80$ meters in the ground surface. The average spatial coherence threshold used was 0.25 , and therefore a total subset of 183161 pixels was selected. Coherence maps were also computed for each interferogram, showing little temporal decorrelation on most of the island, except for the dunes areas which are located in the NW and at the isthmus connecting the Jandía Peninsula (Figure 16). A total of 46 interferograms (Table 1), out of the 78 possible combinations, were selected to retrieve the linear velocity by stacking (average 
unwrapped interferograms). Linear trends of the orbital effects were removed on azimut and

range directions. Unwrapping of Lobos Island was unreliable as there was no connection to the seed.

The linear velocity map of Fuerteventura for each pixel (in mm/year) is shown in Figure 16. Linear velocity is around $1 \mathrm{~mm} /$ year for most of the island. Results at the Jandía Peninsula are different. A net horizontal limit can be noticed at the Western part, which coincides with the Jandía Peninsula hill range (where the highest island altitude is reached). However, it is probably due to the bad quality of the phase unwrapping in the area produced by the poor connections with the rest of the island (limited amount of pixels at the isthmus). Anyway, further investigations could concentrate on that area, using radar observation in another band (e.g., X-band) to study whether or not there are small current displacements. We can conclude that, during the studied period 2003-2010, overall Fuerteventura Island was stable, which is consistent with the lack of recent volcanism of the area.

\subsection{Deformation modeling and designing of the geodetic volcano monitoring.}

Over the last 14 years, constant deformation modelling work has been done to improve direct models considering different characteristics of the media (topography, structure, rheology,...). Charco et al. (2002) compute the effects on the geoid and vertical deflection produced by magmatic intrusions. It is important to estimate the change in the surface of reference for geodetic measurements. Using the elastic-gravitational model (Rundle, 1982; Fernández and Rundle, 1994) it is determined that big magmatic intrusions are necessary to produce non negligible effects on the geoid.

Charco et al. (2007) investigate the effects of topography on surface deformation and gravity changes caused by a magma intrusion in the Earth's crust. They develop a three- 
dimensional (3-D) indirect boundary element method (IBEM) that incorporates realistic

topographic features and show that relevant topography alters both the magnitude and pattern of the deformation and gravity signal. As an example of realistic topography, they consider a spherical source of dilatation located at $4 \mathrm{~km}$ depth below Teide volcano summit (Tenerife, Canary Islands) in order to simulate the deformation and gravity changes that could be observed at Tenerife if a hypothetical intrusion occurred in the volcanic system.

Their approach gives a picture of the 3-D topographic effect at Teide that can provide insight in order to improve the geodetic monitoring of the volcano. Fernández et al. (1999) and Yu et al. (2000) performed a theoretical study of sensitivity to ground deformation and gravity changes to define the most suitable geodetic monitoring system. They considered a flat surface in their methodology, although they pointed out that the results were preliminary and needed corrections for topography. Charco et al. (2007c) employ the IBEM numerical technique in order to perform a theoretical study of sensitivity of the permanent ITER's GPS network installed in the vicinity of Teide volcano (González et al., 2005; Prieto et al., 2005; Fernández et al., 2006). Their study assumes that the displacements and gravity changes are caused by the presence of a shallow magmatic system. They propose some improvements in order to discriminate between different geometries and processes of the magma system considering the related volcanic hazard. It is also shown that microgravity techniques would be a suitable method for monitoring the Teide stratovolcano. They suggest the installation of a gravimeter of continuous recording at some of the GPS locations, particularly in stations located at the volcano flanks where a shallow intrusion beneath the summit of the volcano could cause the maximum deformation and changes in gravity.

Charco and Galán de Sastre (2014) use a finite element model combined with explorative inversion schemes. Their numerical methodology is applied by way of example to Tenerife Island. They study inversion results for synthetic data as observed in the 17 GPS-GNSS network 
stations installed in the Island by the IGN (www.ign.es), the Instituto Tecnológico y de Energías

Renovables (ITER; www.iter.es) and Cartografía de Canarias (GRAFCAN; www.grafcan.es) using different crustal structures. Also, real topography is considered. The inversion needs around 24 hours of computer code running to be obtained.

Fernández and Luzón (2002) complete the work done by Fernández et al. (1999) and Yu et al. (2000), considering the last observational and theoretical results until that date and introducing the use of the new space geodetic techniques, permanent GPS observation and InSAR (see previous sections). They propose an updated geodetic monitoring system including those methodologies, gravity and GNSS networks basically for Tenerife, La Palma and Lanzarote, and a minimum version of it for the rest of the Islands. Obviously their conclusions and proposed geodetic volcano monitoring system for the archipelago should be revised and updated considering the recent volcanic activity in Tenerife and El Hierro and the evolution of all the involved techniques, deformation models and inversion techniques for interpretation.

\section{Discussion and Conclusions.}

We have reviewed most of the geodetic works carried out in the Canary Islands during the $20^{\text {th }}$ century and the beginning of the $21^{\text {st }}$ with a focus on volcanology, considering the technical limitations. The results obtained during the last decades point to some important issues regarding the potential and limitations of a geodetic volcano monitoring system. We can also summarize some perspectives for the future. The last two decades were marked by a clear advance in geodetic techniques (and monitoring possibilities) using satellite technology, continuous GPSGNSS observation and DInSAR. The latter has evolved into the multitemporal DInSAR techniques and their use with error estimation (see e.g., González and Fernández, 2011) together with the new generation of radar satellites help to improve precision and spatial resolution (Joyce 
et al., 2010; Sansosti et al., 2014). Furthermore, multi-satellite and multi-band radar observation

opens new options to minimize revisit time and extract much information for volcano deformation studies (González et al., 2013), and elsewhere using MSBAS (Samsonov et al., 2013). We envision more frequent use of deformation data along with microgravity measurements, as a powerful tool in volcano monitoring and for interpretation of results in the Canary Islands (Gottsmann et al., 2006; Battaglia et al., 2008, Camacho et al., 2011c)

The results of InSAR application has clearly shown the need for considering and properly correcting atmospheric delay, as has been clearly seen for the El Hierro study (Cong et al., 2012; González et al., 2013). Different methodologies can be used to do it: use of GNSS observations (Cong et al., 2012); use of mesoscale meteorological models (Eff-Darwich et al., 2011; Bekaert et al., 2013); or application of a strategy based on an empirical polynomial relationship between atmospheric phase noise and topography (González et al., 2013). Corrections must be systematically applied on the multitemporal DInSAR application to islands with steep topography.

Another clear aspect which should be considered is data integration, mainly using GNSS and multitemporal DInSAR data (Samsonov et al., 2008; González et al., 2010a). Data integration should provide a better definition of the 3D deformation field, ensuring integrity and validation of the observed deformation, and eventually improving results precision.

Efficient performing geodetic volcano monitoring involves knowing the background deformation to be able to clearly detect any significant anomaly in displacement or gravity change. This determination for the entire archipelago is being carried out in the framework of an ESA Category-1 project (Fernández, 2012) for the period 1992-2010 using more than 1,500 radar images. The first results obtained for Fuerteventura Island have been described in this work, this being the first time this Island has been studied to search for surface displacements. 
Other important and basic tools for interpreting any detected anomaly are crustal structural models, deformation models and inversion techniques. In crustal models, it is important to improve the knowledge of the 3D structure in a wider area, covering not only particular Islands, and it can be estimated by combining elevation, gravity, gradiometric, geoid, surface heat flow and seismic data in regional lithospheric models (e.g., Fullea et al., 2013). In direct models and inversion techniques, there are two main needs. First, to obtain a more advanced model, capable of considering more realistic media and sources. In this case, new mathematical tools can help to develop more powerful analytical models (e.g., Arjona et al., 2008). Numerical methodologies as developed by Charco and Galán de Sastre (2014) can also play an important role. Their use in between eruptions can be very useful, considering that if we know a priori information on the site, numerical modeling provides, in a relatively short time, a solution closer to reality. However, this kind of inversion methodology is not useful for near real-time inversion during volcanic crisis due to the codes' running time (at least serveral hours). In these cases, analytical models can be the solution to invert geodetic deformation data obtained in near realtime [e.g., about 30 minutes, García et al. (2014); or less than 1 minute, Camacho et al. (2011c) and Cannavò et al. (2012)], even considering the obtained results are often only first approximations to reality.

Since early 2000, no dedicated strategy has been discussed about the geodetic volcano monitoring for the Canary Islands (Fernández and Luzón, 2002). Since then, new research groups and public institutions have started different activities, shaping a complex landscape. A critical aspect to which more attention should be paid is the optimization of scarce resources. In particular, when geodetic networks are being deployed, it must be acknowledged that multiple partners who are pursuing similar objectives could be involved, so as to avoid duplicate overlapping infrastructure. Clear examples are GPS-GNSS networks on the islands of Tenerife (see above and previous sections) and El Hierro. During El Hierro eruption crisis, two rapid 
response GPS networks clearly expanded the capability to measure deformation on this island, but at the cost of revealing the worse inefficiencies in this complex scenario. As we can see in Figure 17, at best, a lack of communication ended in at least 10 GPS receivers being co-located atn only 5 sites, which in the end did not contribute any new significant ground deformation information, while other parts of the Island remained unmonitored, particularly the Northeast, and the far west. Clearly, the problems were not only logistical, as whenever possible the designers of two GPS networks avoided duplicating the resources available to them, by placing their stations far away from a publicly available one (FRON station from the regional cartographic survey agency), located in an easy-to-access town, Frontera.

Situations, like the one described for El Hierro Island, reflect the need to keep updating the design of a modern and flexible geodetic volcano monitoring system, which considers all the previously described results, tackling the challenges of maximizing resources. Rather than competing for the best sites, a smarter solution would be to spend some time defining joint data sharing policies, that could satisfy all the parties involved, while maximizing the scientific returns of enjoying larger datasets to track activity, test hypotheses and models, etc. This will benefit not only fair competition among researchers, but also foster the required knowledge to improve our understanding of the Canary Islands volcanism, and let the organizations responsible conduct improved monitoring. We propose a strategy, similar to other successful consortiums, where researchers and organizations merge resources to keep instrumentation pools updated, and (cyber) infrastructures that collectively maximize the strengths of a geodetic community. Examples to follow could be the geodesy consortium of UNAVCO in the USA [www.unavco.org], or the Supersites or Natural laboratories concepts sponsored by GEO (Group on Earth Observations) [http://supersites.earthobservations.org/]. Moreover, a starting point would be an agreement to redistribute existing GPS stations and a fair access data policy for research purposes, involving at least the most relevant partners (CSIC, Grafcan, Instituto Geográfico Nacional, ITER- 
INVOLCAN, Universidad Complutense de Madrid, Universidad de Cádiz, University of Leeds,

\section{Acknowledgments.}

This work has been supported by MINECO research project AYA2010- 17448 and ESA CAT1 project 11021. We thank P. Suarez from Cartografía de Canarias SA for the information provided on the classical geodetic networks of the Canary Islands. We thank A. Manconi and one anonymous reviewer for their useful comments and suggestions to improve the manuscript. It is a contribution for the Moncloa Campus of International Excellence.

\section{REFERENCES}

Ablay, G.J., and Kearey, Ph., (2000), Gravity constraints on the structure and volcanic evolution of Tenerife, Canary Islands, J. Geophys. Res., 105, 5783-5796.

Almendros, J., Ibañez, J. M., Carmona, E., and Zandomeneghi, D., (2007), Array analyses of volcanic earthquakes and tremor recorded at Las Cañadas caldera (Tenerife Island, Spain) during the 2004 seismic activation of Teide volcano, J. Volcanol. Geotherm. Res., 160, 285299.

Amelung, F., Yun, S. - H., Walter, T. R., and Segall, P. (2007), Stress control of deep rift intrusion at Mauna Loa volcano, Hawaii, Science, 316, 1026-1030, doi:10.1126/science.1140035.

Ancochea, E., Brändle, J.L., Huertas, M.J., Cubas, C.R., and Hernán, F. (2003), The felsic dikes of La Gomera (Canary Islands): identification of cone sheet and radial dike swarms, Journal of Volcanology and Geothermal Research, 120(3-4), 197-206, doi:10.1016/S03770273(02)00384-0. 
Anguita, F., Garcia Cacho, L., Colombo, F., Camacho, A.G., and Vieira, R. (1991), Roque Nublo caldera: a new stratocone caldera in Gran Canaria, Canary Islands, J. Volcanol. Geotherm. Res., 47, 45-63.

Anguita, F., and Hernan, F. (2000), The Canary Islands origin; a unifying model, Journal of Volcanology and Geothermal Research, 103, 1-26, doi: 10.1016/S0377-0273(00)00195-5

Araña, V., Camacho, A. G., García, A., Montesinos, F. G., Blanco, I., Vieira, R. and Felpeto, A. (2000), Internal structure of Tenerife (Canary Islands) based on gravity, aeromagnetic and volcanological data, J. Volcanol. Geotherm. Research, 103, 43-64

Araña, V. and Fúster, J. M. (1974), La erupción del volcán Teneguía, La Palma, Islas Canarias [The eruption of the Teneguía volcano, La Palma, Canary Islands], Estudios Geol., Vol. Teneguía, 15-18.

Araña, V., and Gómez, F. (1995), Volcanic hazards and risks of Teide volcano (Tenerife, Canary Islands), Per. Mineral., 64, 23-24.

Arjona, A., Díaz, J.I., Fernández, J. and Rundle, J.B. (2008), On the Mathematical Analysis of an Elastic-gravitational Layered Earth Model for Magmatic Intrusion: The Stationary Case, Pure appl. geophys., 165, 1465-1490.

Arjona, A., Monells, D., Fernández, J., Duque, S., and Mallorquí, J. Deformation analysis employing the Coherent Pixel Technique and ENVISAT and ERS images in Canary Islands, In Proc. of 'Fringe 2009' (ed. Lacoste, H.)(ESRIN, Frascati, ESA, SP-677, March 2010) 8 pp. (CD).

Arnoso, J., Weixin, C., Vieira, R., Shiling, T., and Velez, E. Tidal tilt and strain measurements in the Geodynamics Laboratory of Lanzarote. Proc. $13^{\text {th }}$ Int. Symp. Earth Tides, Brussels, 1997. (ed. Ducarme, B. and Pâquet, P.)(Obs. Royal de Belgique, Série Géophysique, Bruxelles 1998) pp. 149-156. 
Arnoso J., Fernandez J., Vieira R., and Van Ruymbeke M. (2000), A preliminary discussion on tidal gravity anomalies and terrestrial heat flow in Lanzarote (Canary Islands), Marees Terrestres Bull Inform, 132, 10271-10282.

Arnoso, J., Fernández, J. and Vieira, R. (2001a), Interpretation of tidal gravity anomalies in Lanzarote, Canary Islands, J. Geodyn., 31, 341-354.

Arnoso J., Vieira R., Velez E., Weixin C., Shiling T., Jun J., and Venedikov A.P. (2001b), Monitoring tidal and non-tidal tilt variations in Lanzarote island (Spain), J. Geod. Soc. Jpn., 47, 456-462.

Arnoso, J., Vieira, R., Velez, E., van Ruymbeke, M., and Venedikov, A.P., (2001c), Studies of tides and instrumental performance of three gravimeters at Cueva de los Verdes (Lanzarote, Spain), J. Geod. Soc. Jpn., 47, 70-75.

Arnoso, J., Montesinos, F.G., and Benavent, M. (2008), Analysis of ground tilt measurements made in El Hierro (Canary Islands). Geophysical Research Abstracts, 10, EGU2008-A01245, 2008, SRef-ID: 1607-7962/gra/EGU2008-A-01245

Arnoso, J., Benavent, M., Bos, M.S., Montesinos, F.G., and Vieira, R. (2011) Verifying the body tide at the Canary Islands using tidal gravimetry observations. J. Geodyn., 51, 358-365, doi: 10.1016/j.jog.2010.10.004.

Arnoso, J., Montesinos, F. G., Benavent, M., and Vélez, E. J. (2012) The 2011 volcanic crisis at El Hierro (Canary Islands): monitoring ground deformation through tiltmeter and gravimetric observations, Geophys. Res. Abstr., 14, EGU2012-5373.

Baldi, P., and Unguendoli, M., Geodetic networks for crustal movements studies, In Lecture Notes in Earth Sciences, 12. Applied Geodesy (ed. Turner, S.)(Springer, Berlin 1987) pp. $135-161$.

Banda, E., Dañobeitia, J.J., Suriñach, E., and Ansorge, J. (1981) Features of crustal structure under the Canary Islands, Earth Planet. Sci. Lett., 55, 11-24,. 
Barbadillo-Fernández, A., and Quirós-Donate, R. (1996) Proyecto REGENTE. Una nueva red geodésica nacional [REGENTE Project. A new national geodetic network], Física de la Tierra, 8, 23-28.

Battaglia, M., Gottsmann, J., Carbone, D. and Fernández, J. (2008), 4D volcano gravimetry. Geophysics, 73, 6, WA3-WA18. doi: 10.1190/1.2977792.

Bekaert, D.P., Hooper, A.J., Wright, T.J. and Walters, R.J. (2013) Robust corrections for topographically-correlated atmospheric noise in InSAR data from large deforming regions, G23C-01. 2013 Fall Meeting, AGU, San Francisco, Calif., 9-13 Dec.

Berardino, P., G. Fornaro, R. Lanari, and E. Sansosti (2002), A new algorithm for surface deformation monitoring based on small baseline differential SAR interferograms, IEEE Trans. Geosci. Remote Sens., 40, 2375-2383, doi:10.1109/TGRS.2002.803792.

Berrocoso, M., Carmona, J., Fernández-Ros, A., Pérez-Peña, A., Ortíz, R., and García, A. (2010), Kinematic model for Tenerife Island (Canary Islands, Spain): Geodynamic interpretation in the Nubian plate context. J. Afr. Earth Sci., 58, 721-733, doi: 10.1016/j.afrearsci.2010.04.005.

Betti, B., Biagi, L., Crespi, H., and Riguzzi, F. (1999), GPS sensitivity analysis applied to nonpermanent deformation control networks, J. Geodesy 73, 158-167.

Blanco-Sánchez, P., Mallorquí, J. J., Duque, S., and Monells, D. (2008), The Coherent Pixels Technique (CPT): An Advanced DInSAR Technique for Nonlinear Deformation Monitoring, Pure Applied Geophysics, 165, 6, 1167-1193

Bock, Y. (1991), Continuous monitoring of crustal deformation, GPS World, 2, 40-47.

Bosshard, E., and MacFarlane, D.J. (1970), Crustal structure of the western Canary Islands from seismic refraction and gravity data. J. Geophys. Res., 75, 4901-4918. 
Brooks, B.A., Foster, J.H., Bevis, M., Frazer, L.N., Wolfe, C.J., and Behn, M. (2006), Periodic slow earthquakes on the flank of Kìlauea volcano, Hawai'i, Earth Planet. Sci. Lett. 246, 207-216. doi:10.1016/j.eps1.2006.03.035.

Bürgmann, R., Rosen, P.A., and Fielding, E.J. (2000), Synthetic aperture radar interferometry to measure Earth's surface topography and its deformation, Annu. Rev. Earth Planet. Sci., 28, 169-209.

Camacho, A.G., Toro, C., and Fernandez, J. Cálculo de la corrección topográfica a las observaciones gravimétricas en la caldera del Teide obtenidas a partir del modelo topográfico digital de la isla de Tenerife [Computation ot the topographic correction for the gravimetric observations in the Teide caldera obtained from the digital topographic model of the Island of Tenerife] (Publ. Semin. Astron. y Geodesia, 162, Madrid, Spain, 1988).

Camacho, A.G., Vieira, R., and Toro, C. (1991) Microgravimetric model of the Las Cañadas caldera (Tenerife), J. Volcanol. Geotherm. Res., 47, 75-80.

Camacho, A.G., Montesinos, F.G., and Vieira, R. (2000), A 3-D gravity inversion by means of growing bodies, Geophysics, 65, 95-101.

Camacho, A.G., Montesinos, F.G., Vieira, R., and Arnoso, J. (2001), Modellig of crustal anomalies for Lanzarote (Canary Islands) in light of gravity, Geophys. J. Int., 47, 403-414.

Camacho, A.G., Fernández, J., González, P.J., Rundle, J.B., Prieto, J.F., and Arjona, A. (2009), Structural results for La Palma Island using 3D gravity inversion. J. Geophys. Res., 114, B05411, doi: 10.1029/2008JB005628.

Camacho, A.G., Fernández, J., and Gottsmann, J. (2011a), A new gravity inversion method for multiple subhorizontal discontinuity interfaces and shallow basins. J. Geophys. Res., 116, B02413, doi: 10.1029/2010JB008023. 
Camacho, A.G., Fernández, J., and Gottsmann, J. (2011b), The 3-D gravity inversion package

GROWTH2.0 and its application to Tenerife Island, Spain, Comput. Geosci., 37, 621-633, doi: 10.1016/j.cageo.2010.12.003.

Camacho, A.G., González, P.J., Fernández, J., and Berrino, G., (2011c), Simultaneous inversion of surface deformation and gravity changes by means of extended bodies with a free geometry: Application to deforming calderas, J. Geophys. Res., 116, B10401, doi: 10.1029/2010JB008165.

Canales, J.P., and Dañobeitia, J.J. (1998), The Canary Islands swell: a coherence analysis of bathymetry and gravity, Geophys. J. Int., 132, 479-488.

Cannavò, F., Camacho, A.G., Scandura, D., Aloisi, M., Bruno, V., González, P.J., Palano, M., Mattia, M., and Fernández, J. (2012), A time evolving distributed model for the ground deformation associated to the May 13th 2008 eruption on Mt. Etna (Italy), 2012 Fall Meeting, AGU, San Francisco, Calif., 3-7 Dec.

Carracedo, J.C., Pérez-Torrado, F.J., Paris, R., and Rodríguez Badiola, E. (2009), Megadeslizamientos en las Islas Canarias, Enseñanza de las Ciencias de la Tierra, 17, 44-56.

Carracedo, J. C., Pérez Torrado, F., Rodríguez González, A., Soler, V., Fernández Turiel, J. L., Troll, V. R., and Wiesmaier, S. (2012), The 2011 submarine volcanic eruption in El Hierro (Canary Islands), Geol. Today, 28, 53-58, doi:10.1111/j.1365-2451.2012.00827.x .

Carrasco, D., Fernandez, J., Romero, R., Martinez, A., Moreno, V., and Araña, V., Operational volcano monitoring for decision support demonstration. In Proceedings of the Fringe '99 Workshop Advancing ERS SAR Interferometry from Applications towards Operations, November 1999. (ed. European Space Agency) (ESA Publications Division, SP-478, Liege, Belgium, 2000a).

Carrasco, D., Fernández, J., Romero, R., Araña, V., Martínez, V., Moreno, V., Aparicio, A., and Paganini, M.. First results from operational volcano monitoring in the Canary Islands. In 
ESA ERS-ENVISAT Symposium "Looking down to Earth in the New Millennium" (ed.

European Space Agency)(Chalmers University of Technology, Gothenburg, Sweden, 2000).

Casu, F., Manzo, M., and Lanari, R. (2006), A quantitative assessment of the SBAS algorithm performance for surface deformation retrieval from DInSAR data, Remote Sens. Environ., 102, 3-4, 195-210, doi:10.1016/j.rse.2006.01.023.

Caturla, J. L., Compendio de los Sistemas Geodésicos de España. Publicación técnica núm. 1/1978 [Compendium of Geodetic Reference Systems in Spain] (Instituto Geográfico Nacional, Madrid, Spain, 1978) 30 pp.

Caturla, J. L., REGCAN95, Nueva Red Geodésica de las Islas Canarias [REGCAN95, New Geodetic Network for the Canary Islands] (Instituto Geográfico Nacional, Área de Geodesia. Internal Report, Madrid, Spain, 1996) 45 pp.

Caturla, J. L., and Prieto, J., Utilización del Sistema GPS en Proyectos Cartográficos [Using the GPS system in Carthographic projects] (Instituto Geográfico Nacional, Las Palmas de Gran Canaria, Spain, 1996) 376 pp.

Cayol, V., and Cornet, H. (1998), Effects of topography on the interpretation of the deformation field of prominent volcanoes: application to Etna. Geophys. Res. Lett. 25, 1979-1982.

CGMW, Commission for the Geological Map of the World. (2010), Tectonic Map of Africa [Map], retrieved from http://ccgm.free.fr/Africa_Tecto_GB.html

Charco, M., Fernández, J., Sevilla, M.J., and Rundle, J.B. (2002), Modeling magmatic intrusion's effects on the geoid and vertical deflection. Application to Lanzarote, Canary Islands, and Long Valley Caldera, California, Física de la Tierra, 14, 11-31.

Charco, M., Luzón, F., Fernández, J., Tiampo, K.F., and Sánchez-Sesma, F.J. (2007), Threedimensional indirect boundary element method for deformation and gravity changes in 
volcanic areas. Application to Teide volcano (Tenerife, Canary Islands). Journal of

Charco, M., and Galán del Sastre, P. (2014), Efficient inversión of three-dimensional finite element models of volcano deformation. Geophys. J. Int., 196, 3, 1441-1454, doi:10.1093/gji/ggt490.

Chávez-García, F.J., Luzón, F., Raptakis, D., and Fernández, J., (2007), Shear-wave velocity structure around Teide volcano: results using microtremors with the SPAC method and implications for interpretation of geodetic results. Pure appl. geophys., 164, 697-720.

Collier, J. S., and Watts, A. B. (2001), Lithospheric response to volcanic loading by the Canary Islands: Constraints from seismic reflection data in their flexural moats, Geophys. J. Int., $147,660-676$.

Cong, X., Eineder, M., and Fritz, T. Atmospheric delay compensation in differential SAR Interferometry for volcanic deformation monitoring-Study case: El Hierro, In Proc. 2012 IEEE International Geoscience and Remote Sensing Symposium (IGARSS), 3887-3890 (ed: Geoscience and Remote Sensing Society)(Institute of Electrical and Electronics Engineers, Munich, Germany, 2012).

Crossley, D., Hinderer, J., and Riccardi, U. (2013), The measurement of surface gravity, Rep. Prog. Phys., 76, 046101, (47, doi: 10.1088/0034-4885/76/4/046101.

Dash, B.P., and Bosshard, E. (1969), Seismic and gravity investigations around the western Canary Islands, Earth Planet. Sc. Lett., 7, 169-177.

Day, S., Carracedo, J.C., Guillou, H., and Gravestock, P. (1999), Recent structural evolution of the Cumbre Vieja Volcano, La Palma, Canary Islands: volcanic rift zone reconfiguration as a precursor to volcanic flank instability? J. Volcanol. Geotherm. Res. 94, 1-4, 135-167. 
del Rey, R., Ortíz, R., and Fernández, J. (1994), Sismicidad en Timanfaya. Primeros estudios de

Diéz-Gil, J.L., Fernández, J., Vieira, R., and Rundle, J.B. (1994), Modelos de deformación para el diseño de la vigilancia geodésica de actividad volcánica en Lanzarote [Deformation models for the design of geodetic monitoring of volcanic activity in Lanzarote]. Serie Casa Volcanes, Cabildo Insular Lanzarote, 3, 61-78.

Dixon, T.H., Mao, A., Bursik, M., Heflin, M., Langbein, J., Stein, R., and Webb, F. (1997), Continuous monitoring of surface deformation at Long Valley caldera, California, with GPS, J. Geophys. Res., 102, 17-34.

Dong, D., and Bock, Y, (1989), Global Position System network analysis with phase ambiguity resolution applied to crustal deformation studies in California, J. Geophys. Res., 94, 39493966.

Dvorak, J.J., and Dzurisin, D. (1997), Volcano geodesy; the search for magma reservoirs and the formation of eruptive event, Rev. Geophys. 35, 343-384.

Dzurisin, D., Volcano deformation: Geodetic monitoring techniques. (Springer-Praxis Books in Geophysical Sciences. Praxis Publishing Ltd., Chichester, UK., 2007)

Eff-Darwich, A., Grassin, O., and Fernández, J. (2008), An upper limit to ground deformation in the Island of Tenerife, Canary Islands, for the period 1997-2006, Pure and Applied Geophysics, 165, 6, 1049-1070. DOI: 10.1007/s00024-008-0346-7.

Eff-Darwich, A., Pérez-Darias, J.C., Fernández, J., García-Lorenzo, B., González-Fernández, A., and González, P.J. (2012), Using a Mesoscaale metheorological model to reduce the effect of tropospheric water vapour from DInSAR data: A case study for the Island of Tenerife, Canary Islands, Pure appl. Geophys., 169, 1425-1441. DOI 10.1007/s00024-011-0401-4. 
Fernández, J. (1991), Investigations on volcanic risk in Lanzarote. I- Model for gravity variations

and deformations originated by a magmatic intrusion in the crust. Comptes Rendus, JLG. Conseil de L'Europe, 72, 49-55.

Fernández, J., and Vieira, R. (1991), Investigations on volcanic risk in Lanzarote. II- Some observational methods, Comptes Rendus, JLG. Conseil de L'Europe, 72, 56-59.

Fernández, J., Vieira, R., Díez, J.L., and Toro, C. (1991), Study about the relationship among crustal thickness, heat flow and gravimetric tide in the island of Lanzarote, Comptes Rendus, JLG. Conseil de L'Europe, 72, 17-22.

Fernandez, J., Vieira, R., Diez, J.L., and Toro, C. (1992), Investigations on crustal thickness, heat flow and gravity tide relationship in Lanzarote island. Phys Earth Planet Interiors, 74,199208.

Fernandez, J., Técnicas geodésicas y geodinámicas aplicadas a la investigación en riesgo volcánico en la isla de Lanzarote [Geodetic and geodynamic techniques applied to research on volcanic risk in Lanzarote] (Ph. D. Thesis,Universidad Complutense de Madrid, Madrid, Spain, 1993) 149 pp.

Fernández, J., Arnoso, J., and Vieira, R. (1993), Investigación en riesgo volcánico en Lanzarote [Volcanic risk research in Lanzarote], Revista de la Real Academia de Ciencias Exactas, Físicas y Naturales de Madrid, Tomo LXXXVIII, Cuad. $2^{\circ}$ y 3o $479-484$.

Fernández, J., and Rundle, J.B. (1994), Gravity Changes and deformation due to a magmatic intrusion in a two-layered crustal model, J. Geophys. Res. 99, 2737-2746.

Fernández, J., Vieira, R., Venedikov, A.P., and Díez, J.L. (1994), Vigilancia de riesgo volcánico en Canarias. Isla de Lanzarote [Monitoring volcanic risk in the Canary Islands. Lanzarote Island], Física de la Tierra, 5, 77-88.

Fernández, J., and Diez, J.L. (1995), Volcano monitoring design in Canary Islands by deformation model, Cahiers Centre Eur. Geodynam. Seismol., 8, 207-217. 
Fernández, J., Carrasco, J. M., Rundle, J. B. and Araña, V. (1999), Geodetic methods for

Fernández, J., Charco, M., Tiampo, K. F., Jentzsch, G., and Rundle, J. B. (2001a), Joint interpretation of displacements and gravity changes in volcanic areas. A test example: Long Valley Caldera, California, Geophys. Res. Lett., 28, 1063-1066.

Fernandez, J., Tiampo, K. F., Jentzsch, G., Charco, M., and Rundle, J. B. (2001b), Inflation or deflation? New results for Mayon volcano applying elastic-gravitational modeling, Geophys. Res. Lett., 28, 2349-2352.

Fernández, J., and Luzón, F. (2002), Geodetic monitoring in Canary Islands. Present and new perspectives, Física de la Tierra, 14, 109-126.

Fernández, J., Romero, R., Carrasco, D., Luzón, F. and Araña, V. (2002), InSAR Volcano and Seismic Monitoring in Spain. Results for the Period 1992-2000 and Possible Interpretations, Opt. Laser Eng., 37, 285-297.

Fernández, J., Yu, T. T., Rodriguez-Velasco, G., González-Matesanz, J., Romero, R., Rodríguez, G., Quirós, R., Dalda, A., Aparicio, A. and Blanco, M. J. (2003), New geodetic monitoring system in the volcanic island of Tenerife, Canaries, Spain. Combination of InSAR and GPS techniques, J. Volcanol. Geotherm. Res., 124, 241-253.

Fernández, J., González-Matesanz, F. J., Prieto, J. F., Rodríguez-Velasco, G., Staller, A., AlonsoMedina, A. and Charco, M. (2004), GPS Monitoring in the N-W Part of the Volcanic Island of Tenerife, Canaries, Spain: Strategy and Results, Pure appl. Geophys., 161, 1359-1377.

Fernández, J., Romero, R., Carrasco, D., Tiampo, K. F., Rodríguez-Velasco, G., Aparicio, A., Araña, V. and González-Matesanz, F. J. (2005), Detection of displacements on Tenerife Island, Canaries, using radar interferometry, Geophys. J. Int., 160, 33-45.

Fernández J., Camacho, A.G., Prieto, J.F., González, P., Rodríguez-Velasco, G., Tunini, L., Willert, V., Calvo, D., Sagiya, T., Fujii, N., Charco, M., Hernández, P.A., Pérez, N.M., 
Mallorquí, J., González-Matesanz, J., Valdés, M., López.Turbay, A.A., and Carrasco, D.

(2006), Geodetic Observation of Tenerife volcanic unrest. Results and interpretation.

GARAVOLCAN 2006, 300th Anniversary Volcano Conference Commemorating the 1706 Arenas Negras Eruption, Garachico, Tenerife, Canary Islands, 22-27 May, 2006.

Fernández, J., Camacho, A.G., González, P.J., Samsonov, S., Prieto, J.F., Tiampo, K.F., Gottsmann, J., Puglisi, G., Guglielmino, J., Mallorquí, J.J., Tunini, L., Willert, V., Rodríguez-Velasco, G., Charco, M., Navarrete, D., Duque, S., Carrasco, D., BlancoSánchez, and P (2007), Tenerife island (Canaries, Spain) unrest, 2004-2006, studied via integrated geodetic observations. In Proceedings of the 2007 International Geohazards Week, 5-9 November 2007, . (ed. ESA-ESRIN) (ESA Publications Division, Frascati, Italy, 2007)

Fernández, J., Samsonov, S., Camacho, A.G., González, P.J., Prieto, J.F., Tiampo, K.F., Rodriguez-Velasco, G., Tunini, L., Willert, V., Charco, M., Mallorquí, J.J., and Carrasco, D. (2008), Integration of two line-of-sights classical DInSAR and GPS data to study the 2004-2006 Tenerife volcanic unrest, Geophys. Res. Abstracts, 10, EGU2008-A-10611.

Fernández, J., Tizzani, P., Manzo, M., Borgia, A., González, P.J., Martí, J., Pepe, A., Camacho, A.G., Casu, F., Berardino, P., Prieto, J.F. and Lanari, R. (2009), Gravity-driven deformation of Tenerife measured by InSAR time series analysis Geophys. Res. Lett., 36, L04306, doi:10.1029/2008GL036920.

Fernández, J. [PI], (2012), Determination of the 1992-2010 deformation field in the Canary Islands by means of ERS-1/2, ENVISAT and ALOS radar images: Implications in the volcano monitoring system definition. (Cat.-1 11021) European Space Agency (ESA) (04/2012-03/2015).

Filmer, P.E., McNutt, and M.K. (1989), Geoid anomalies over the Canary Islands group. Mar. Geophys. Res., 11, 77-87. 
Folger, D.W., McCullough, J.R., Irwin, B.J., and Dodd, J.E. (1990), Map showing free-air gravity anomalies around the Canary Islands, Spain [Map]. U.S. Geological Survey Miscellaneous Field Studies Map MF-2098-B, scale 1:75,000.

Fullea, J., Camacho, A.G., and Fernández, J. (2013), 3D Coupled geophysical - petrological modelling of the Canary Islands and North - Western african margin lithosphere. 15th Annual Conference of the Int. Ass. Mathematical Geosciences, Madrid, Septiembre 2-6, 2013.

García, A., Fernández-Ros, A., Berrocoso, M., Marrero, J.M., Prates, G., De la Cruz-Reyna, S., and Ortiz, R. (2014), Magma displacements under insular volcanic fields, applications to eruption forecasting: El Hierro, Canary Islands, 2011-2013, Geophys. J. Int., 197,1, 322334, doi: 10.1093/gji/ggt505.

García, L., Cano, M. A., Ortiz, E. and Sevilla, M. J. (2002), Determinación de coordenadas provisionales de la estación GPS permanente de Lanzarote [Computation of interim coordinates for the permanent GPS station of Lanzarote], Comunicaciones de la $3^{a}$ Asamblea Hispano-Portuguesa, 4 p.

García-Cañada, L., and Sevilla, M.J., Monitoring crustal movements and sea level in Lanzarote. In Geodetic deformation monitoring: from geophysical to engineering roles (Ed. Sansò, F., and Gil, A.J.) (International Association of Geodesy Symposia, 131, Springer-Verlag, Berlin, Germany, 2006) pp. 160-165.

Geldmacher, J., Hoernle, K., van den Bogaard, P., Duggen, S., Werner, R. (2005), New 40Ar/39Ar age and geochemical data from seamounts in the Canary and Madeira volcanic provinces: support for the mantle plume hypothesis, Earth Planet Sci Lett 237,85-101

Gil Montaner, F, (1929a). Trabajos geodésicos de primer orden en Canarias y Marruecos [First order geodetic campaigns in the Canaries and Morocco]. Boletín de la Real Sociedad Geográfica, LXIX, 141-156. 
Gil Montaner, F., Últimos trabajos geodésicos en Canarias y Marruecos [Latest geodetic campaigns in the Canaries and Morocco] (Instituto Geográfico y Catastral, Madrid, Spain, 1929b) $23 \mathrm{pp}$.

González, P.J., Prieto, J.F., Fernández, J., Sagiya, T., Fujii, N., Hernández, P.A., and Pérez, N.M. (2005), Permanent GPS observation in Tenerife Island for volcano monitoring. Results obtained from May 2004 to present. Geophysical Research Abstracts, 7, 09545.

González, P.J., Samsonov, S., Manzo, M., Prieto, J.F., Tiampo, K.F., Tizzani, P., Casu, F., Pepe, A., Berardino, P., Camacho, A.G., Lanari, R., and Fernández, J. (2010a), 3D volcanic deformation fields at Tenerife Island: integration of GPS and Time Series of DInSAR (SBAS), Cahiers Centre Eur. Geodynam. Seismol., 29, 44-50. ISBN: 978-2-91989-708-7.

González, P. J., Tiampo, K. F., Camacho, A. G. and Fernández, J. (2010b), Shallow flank deformation at Cumbre Vieja volcano (Canary Island): Implications on the stability of steepsided volcano flanks at oceanic islands, Earth Planet. Sc. Lett., 297, 545-557

González, P. J. and Fernández, J. (2011), Error estimation in multitemporal InSAR deformation time series, with application to Lanzarote, Canary Islands. J. Geophys. Res., 116, B10404 González, P. J.,. Samsonov, S. V, Pepe, S., Tiampo, K. F., Tizzani, P., Casu, F., Fernández, J., Camacho, A. G., and Sansosti, E. (2013), Magma storage and migration associated with the 2011-2012 El Hierro eruption: Implications for crustal magmatic systems at oceanic island volcanoes, J. Geophys. Res. Solid Earth, 118, 4361-4377, doi:10.1002/jgrb.50289.

Gorbatikov, A.V., Kalinina, A.V., Volkov, V.A., Arnoso, J., Vieira, R., and Vélez, E. (2004), Results of analysis of the data of microseismic survey at Lanzarote Island, Canary, Spain, Pure appl. geophys., 161, 1561-1578.

Gorbatikov, A.V., Montesinos, F.G., Arnoso, J., Stepanica, M.Y., Benavent, M., and Tsukanov, A.A. (2013), New features in the subsurface structure model of El Hierro Island (Canaries) 
from low-frecuency microseismic sounding: an insight into the 2011 seismo-volcanic crisis,

Surv. Geophys., 34, 463-489, doi: 10.1007/s10712-013-9240-4.

Gottsmann, J., Wooller, J., Martí, J., Fernández, J., Camacho, A., González, P., García, A., and Rymer, H. (2006), New evidence for the reawakening of Teide volcano, Geophys. Res. Lett., 33, L20311, doi: 10.1029/2006GL027523.

Gottsmann, J., Camacho, A.G., Martí, J., Wooller, L., Fernández, J., García, A. and Rymer, H. (2008), Shallow structure beneath the Central Volcanic Complex of Tenerife from new gravity data: Implications for its evolution and recent reactivation. Phys. Earth Planet. Int., $168,212-230$.

Groten, E., and Becker, M. (1995), Methods and experiences of high precision gravimetry as a tool for crustal movement detection. J. Geodyn., 19,141-157.

Hanssen, R. F., Radar Interferometry. Data interpretation and error analysis, (Kluwer Academic publ., Dordrecht, The Netherlands, 2001) 308 pp.

Harris, A.J.L., Butterworth, A.L., Carlton, R.W., Downey, I., Miller, P., Navarro, P., and Rothery, D.A. (1997), Low-cost volcano surveillance from space: case studies from Etna, Krafla, Cerro Negro, Fogo, Lascar and Erebus, Bull. Volcanol., 59, 49-64.

Hayford, J. F., Supplementary Investigation in 1909 of the Figure of the Earth and Isostasy, (Separate publications, U.S. Coast and Geodetic Survey, U.S. Government Printing Office, Washington, D.C., 1910) $80 \mathrm{pp}$

Hernández-Pacheco, A. and Vals, M. C. (1982), The historical eruptions of La Palma Island (Canarias), Arquipelago. Rev. Univ. Azores, Ser. C. Nat., 3, 83-94.

Hoernle, K. and Carracedo, J. C., Canary Islands geology, In Encyclopedia of Islands (ed. Gillespie, R. D., and Clague, D. A.) (University of California Press, Berkeley, California, USA, 2009), pp. 133-143. 
Hugentobler, U., Schaer, S., and Fridez, P. [Eds.], Bernese GPS software version 4.2

(Astronomical Institute, University of Berne, 2001) 515 pp.

Ibáñez, J.M., De Angelis, S., Díaz-Moreno, A., Hernández, P., Alguacil, G., Posadas, A., and Pérez, N. (2012), Insights into the 2011-2012 submarine eruption off the coast of El Hierro (Canary Islands, Spain) from statical analysis of earthquake activity. Geophys. J. Int., 191, 2, 659-670, doi: 10.1111/j.1365-246X.2012.05629.x

IGC, Instituto Geográfico y Catastral., Espagne. Rapports sur les travaux géodésiques, astronomiques et gravimétriques exècutes par l'Institut Géographique de 1933 a 1936 présentés à la VI Assemblée Génèrale de l'Association de Géodésie de l'Union Géodésique et Géopysique Internationale (Ateliers de l'Institut Géographique et Cadastral, Madrid, Spain, 1938), 33pp.

IGC, Instituto Geográfico y Catastral, Islas Canarias. Cálculo compensado de las coordenadas UTM de las Islas Canarias [Canary Islands. Adjusted computations of UTM coordinates of the Canary Islands] (Instituto Geográfico y Catastral, Madrid, Spain, 1968)

IGN (2006), Boletín de sísmos próximos [Data archive], retrieved from http://www.geo.ign.es.

Johnson, H.O., and Wyatt, F.K. (1994), Geodetic network design for fault-mechanics studies, Manuscripta Geodaetica 19, 309-323.

Joyce, K., Wright, K., Ambrosia, V., and Samsonov, S. (2010), Incorporating remote sensing into emergency management, The Australian Journal of Emergency Management, 25, 4, 14 23.

Jung, W.Y., and Rabinowitz, P.D. (1986), Residual geoid anomalies of the north Atlantic ocean and their tectonic implications. J. Geophys. Res., 91, 10383-10396.

Kalinina, A.V., Volkov, V.A., Gorbatikov, A.V., Arnoso, J., Vieira, R., and Benavent, M. (2004), Tilt observations in the nomal mode frecuency band at the geodynamic observatory Cueva 
de los Verdes, Lanzarote, Pure appl. geophys., 161, 1597-1611. Doi: 10.1007/s00024-0042423-4.

Kröchert, J., Maurer, H., and Buchner, E. (2008), Fossil beaches as evidence for significant uplift of Tenerife, Canary Islands, Journal of African Earth Sciences, 51, 4, 220-234, doi:10.1016/j.jafrearsci.2008.01.005

Llanes, M.P., Estructura de la litosfera en el entorno de las Islas Canarias a partir del análisis gravimétrico e isostático: implicaciones geodinámicas [Lithosphere structure on the Canary Islands from gravimetric and isostatic analysis: geodynamic implications] (Ph.D. Thesis., Univ. Complutense de Madrid, Madrid, Spain, 2006).

López, C., Blanco, M. J., Abella, R., Brenes, B., Cabrera Rodríguez, V. M., Casas, B., Domínguez Cerdeña, I., Felpeto, A., Fernández de Villalta, M., del Fresno, C., García, O., García-Arias, M. J., García-Cañada, L., Gomis Moreno, A., González-Alonso, E., Guzmán Pérez, J., Iribarren, I., López-Díaz, R., Luengo-Oroz, N., Meletlidis, S., Moreno, M., Moure, D., Pereda de Pablo, J., Rodero, C., Romero, E., Sainz-Maza, S., Sentre Domingo, M. A., Torres,P. A., Trigo, P., and Villasante-Marcos, V. (2012), Monitoring the volcanic unrest of El Hierro (Canary Islands) before the onset of the 2011-2012 submarine eruption, Geophys. Res. Lett., 39, L13303, doi:10.1029/2012GL051846.

MacFarlane, D.J., and Ridley, W.I. (1968), An interpretation of gravity data for Tenerife, Canary Islands, Earth Planet. Sc. Lett., 4, 481-486.

MacFarlane, D.J., and Ridley, W.I. (1969), An interpretation of gravity data for Lanzarote, Canary Islands, Earth Planet. Sc. Lett., 6, 431-436.

Mallorquí, J.J., Mora, O., Blanco, P,. and Broquetas, A., Linear and non-linear long-term terrain deformation with DInSAR (CPT: Coherent Pixels Tehcnique), In Proc. of FRINGE 2003 Workshop(ed. European Space Agency) (ESA Publications Division, 2003) pp. 1-8. 
Martí, J., Pinel, V., López, C., Geyer, A., Abella, R., Tárraga, M., Blanco, M.J., Castro, A., and

Rodríguez, C. (2013), Causes and mechanisms of the 2011-2012 El Hierro (Canary Islands) submarine eruption, J. Geophys. Res. Solid Earth, 118, 8123-839, doi: 10.1002/jgrb.50087.

Massonnet, D. and Feigl, K. (1998), Radar interferometry and its application to changes in the Earth's surface, Rev. Geophysics, 36, 441-500.

Massonnet, M., and Sigmundsson, F., Remote sensing of volcano deformation by radar interferometry from Various Satellites. Geophysical Monographs 116 (Am. Geophys. Union, Washington, DC, 2000), pp 207-221.

McGovern, P. J. (2007), Flexural stresses beneath Hawaii: Implications for the October 15, 2006, earthquakes and magma ascent, Geophys. Res. Lett., 34, L23305, doi:10.1029/2007GL031305.

Merle, O., and A. Borgia (1996), Scaled experiments of volcanic spreading, J. Geophys. Res., $101,13,805-13,817$.

Mezcua, J., Buforn, E., Udías, A. and Rueda, J. (1992), Seismotectonics of the Canary Islands, Tectonophysics, 208, 4, 447-452.

Minshull, T. A., and Charvis, P. (2001), Ocean island densities and models of lithospheric flexure, Geophys. J. Inter., 145, 731-739, doi:10.1046/j.0956-540x.2001.01422.x.

Montgomery - Brown, E. K., Sinnett, D. K., Poland, M., Segall, P., Orr, T., Zebker, H., and Miklius, A. (2010), Geodetic evidence for en echelon dike emplacement and concurrent slow slip during the June 2007 intrusion and eruption at Killauea volcano, Hawaii, J. Geophys. Res., 115, B07405, doi:10.1029/2009JB006658.Montesinos, F.G., 1999. Inversión gravimétrica 3D por técnicas de evolución. Aplicación a la isla de Fuerteventura [3D gravimetric inversion by evolution techniques. Application to the Island of Tenerife] (Ph.D. Thesis, Complutense University of Madrid, Spain, 1999) 
Montesinos, F.G., Arnojo, J., and Vieira, R. (2005), Using a genetic algorithm for 3-D inversión of gravity data in Fuerteventura (Canary Islands), Int. J. Earth Sci., 94, 301-316.

Montesinos, F.G., Arnoso, J., Benavent, M., and Vieira, R. (2006), The crustal structure of El Hierro (Canary Islands) from 3-D gravity inversion, J. Volcanol. Geotherm. Res., 150, 283-299.

Montesinos, F.G., Arnoso, J., Vieira, R., and Benavent, M. (2011), Subsurface geometry and structural evolution of La Gomera Island based on gravity data, J. Volcanol. Geotherm. Res., 199, 105-117, doi: 10.10161/j.volgeores.2010.10.007.

Morgan, W. J. (1971), Convection plumes in the lower mantle, Nature, 230, 5288, 42-43, doi:10.1038/230042a0

Moss, J. L., McGuire, W. J. and Page, D. (1999), Ground deformation monitoring of a potential landslide at La Palma, Canary Islands, J. Volcanol. Geotherm. Research, 94, 251-265.

Okada, Y. (1985), Surface deformation due to shear and tensile faults in a half-space, Bull. Seismol. Soc. Am. 75, 1135-1154.

Pérez, N.M and Hernández, P.A. (2004), Reducing Volcanic Risk in the Canary Islands: are we doing the homework. International Symposium "Reducing Volcanic Risk in Islands", Granadilla de Abona, Tenerife, Canary islands, Spain.

Pérez, N. M., Melián, G., Galindo, I., Padrón, E., Hernández, P. A., Nolasco, D., Salazar, P., Pérez, V., Coello, C., Marrero, R., González, Y., González, P. and Barrancos, J. (2005), Premonitory geochemical and geophysical signatures of volcanic unrest at Tenerife, Canary Islands, Geophysical Research Abstracts, 7.

Pérez, N. M., Hernández, P. A., Padrón, E., Melián, G., Marrero, R., Padilla, G., Barrancos, J. and Nolasco, D. (2007), Precursory subsurface 222Rn and 220Rn degassing signatures of the 2004 seismic crisis at Tenerife, Canary Islands, Pure appl. geophys., 164, 2431-2448. 
Perlock, P.A., Gonzalez, P. J., Tiampo, K.F., Rodriguez-Velasco, G., and Fernandez, J. (2008),

Time evolution of deformation using Time Series of differential interferograms: Application to La Palma Island (Canary Islands), Pure appl. geophys., 165, 1531-1554.

Prates, G., García, A., Fernández-Ros, A., Marrero, J.M., Ortiz, R., and Berrocoso, M. (2013), Enhancement of sub-daily positioning solutions for Surface deformation surveillance at El Hierro volcano (Canary Islands, Spain), Bull. Volcanol., 75, 724, doi: 10.1007/s00445013-0724-3.

Prieto, J.F., Fernández, J., González, P.J., Sagiya, T., Fujii, N., Hernández, P.A., and Pérez, N.M. (2005), Permanent ITER-GPS network in Canary Islands for volcano monitoring: Design, objectives and first results, Geophysical Research Abstracts, 7, 09426.

Prieto, J., González, P., Seco, A., Rodríguez-Velasco, G., Tunini, L., Perlock, P., Arjona, A., Aparicio, A., Camacho, A., Rundle, J., Tiampo, K., Pallero, J., Pospiech, S., and Fernández, J. (2009), Geodetic and Structural Research in La Palma, Canary Islands, Spain: 19922007 Results, Pure appl. geophys., 166, 1461-1484.

Puglisi, G., and Coltelli, M. (2001), SAR Interferometry applications on active volcanoes: state of the art and perspectives for volcano monitoring, Il Nuovo Cimento, 24C, 133-145.

Quaas, R., González, R., Guevara, E., Ramos, E., and De La Cruz-Reyna, S. , Monitoreo Volcánico: Instrumentación y Métodos de Vigilancia [Volcanic Monitoring: Instrumentation and Surveillance Methods], In Volcán Popocatépetl, Estudios Realizados Durante la Crisis de 1994-1995 (Ed Zepeda, O., and Sánchez, T. A.) (Centro Nacional de Prevención de Desastres, Universidad Nacional Autónoma de México, México, D.F., 1996) pp. 25-76.

Ranero, C.R., Torne, M., and Banda, E. (1995), Gravity and multichannel seismic reflection constraints on the lithospheric structure of the Canary swell, Mar. Geophys. Res., 17, 519534. 
Rodríguez-Velasco, G., Romero, R., Yu, T. T., González-Matesanz, F. J., Quirós, R., Dalda, A.,

Aparicio, A., Carrasco, D., Prieto, J. F,. and Fernández, J. (2002), On the monitoring of surface displacement in connection with volcano reactivation in Tenerife, Canary Islands, using space techniques, Física de la Tierra, 14, 85-108.

Romero, C., Actividad Volcánica Histórica en las Islas Canarias [Historic volcano activity in the Canary Islands], In Curso Internacional de Volcanología y Geofísica Volcánica (Ed. Astiz, M., and García, A.) (Serie Casa de los Volcanes 7, Cabildo Insular de Lanzarote, Lanzarote, Islas Canarias, 2000) pp. 115-128.

Romero, R., Fernández, J., Carrasco, D., Luzón, F., Martínez, F., Rodríguez-Velasco, G., Moreno, V., Araña, V., and Aparicio, A. (2002), Synthetic Aperture Radar Interferometry (InSAR): Application to ground deformations studies for volcano and seismic monitoring, Física de la Tierra, 14, 55-84.

Romero, R., Carrasco, D., Araña, V. and Fernández, J. (2003), A new approach to the monitoring of deformation on Lanzarote (Canary Islands): an 8-year perspective, Bull. Volcanol., 65, $1-7$.

Romero Ruiz, C., García-Cacho, L., Araña, V., Yanes Luque, A., and Felpeto, A. (2000), Submarine volcanism surrounding Tenerife, Canary Islands: implications for tectonic controls, and oceanic shield forming processes, J. Volcanol. Geotherm. Res., 103, 105-119.

Rundle, J.B. (1982), Deformation, gravity, and potential changes due to volcanic loading of the crust, J. Geophys. Res. 87, 10729-10744 (correction: J. Geophys. Res., 88: 10647-10652, 1983).

Sagiya, T., Miyazaki, S. and Tada, T. (2000), Continuous GPS array and present-day crustal deformation of Japan, Pure appl. geophys., 157, 2303-2322.

Sagiya, T., Barrancos, J., Calvo, D., Padrón, E., Hernández, G. H., Hernández, P. A., Pérez, N., and Suárez, J. M. P. (2012), Crustal deformation during the 2011 volcanic crisis of El 
Hierro, Canary Islands, revealed by continuous GPS observation, Geophys. Res. Abstr., 14, EGU2012-10243.

Samsonov, S., Tiampo, K., Gonzalez, P. J., Prieto, J., Camacho, A. G., and Fernandez, J. (2008), Surface deformation studies of Tenerife Island, Spain from joint GPS-DInSAR observations, In Proc. of Second Workshop on USE of Remote Sensing Techniques (USEReST) for Monitoring Volcaonoes and Seismogenic Areas, Naples, Italy, 11-14 Nov, (IEEE Xplore 10443679, Naples, Italy, 2008) pp. 1-6.

Samsonov, S.V., González, P.J., Tiampo, K.F., Camacho, A.G., and Fernández, J., Spatiotemporal analysis of ground deformation at Campi Flegrei and Mt Vesuvius, Italy, observed by Envisat and Radarsat-2 InSAR during 2003-2013, In Mathematics of Planet Earth. Proc. 15th Annual Conference of the Int. Ass. Mathematical Geosciences. Lecture Notes in Earth Systen Sciences (ed. Pardo-Igúzquiza, E., Guardiola-Albert, C., Heredia, J., Moreno-Merino, L., Durán, J.J., and Vargas-Guzmán, J.A.) (Springer-Verlag Berlin Heidelberg, ISBN: 978-3-642-32407-9. doi: 10.1007/978-3-642-32408-6_84, 2014) pp. $377-382$

Sansosti, E., Berardino, P., Bonano, M., Calò, F., Castaldo, R., Casu, F., Manunta, M. Manzo, M., Pepe, A., Pepe, S., Solaro, G., Tizzani, P., Zeni, G., and Lanari, R. (2014), How second generation SAR systems are impacting the analysis of ground deformation. International Journal of Applied Earth Observation and Geoinformation, 28, 1-11, doi:10.1016/j.jag.2013.10.007.

Segall, P., and Matthews, M. (1997), Time dependent inversion of geodetic data, J. Geophys. Res. $102,22931-22409$.

Segall, P., Desmarais, E.K., Shelly, D., Miklius, A., and Cervelli, P. (2006), Earthquakes triggered by silent slip events on Kilauea volcano, Hawaii, Nature 442. doi:10.1038/nature04938. 
Sevilla, M.J., and Parra, R. (1975), Levantamiento gravimétrico de Lanzarote [Gravimetric survey of Lanzarote], Revista de la Real Academia de Ciencias Exactas, Físicas y Naturales de Madrid, Tomo LXIX, Cuad. 2º 257-284.

Sevilla, M. J., and Martín, M. D. (1986), Geodetic network design for crustal deformation studies in the Caldera of Teide area. Tectonophysics, 130, 235-248.

Sevilla, M. J., Martín, M. D., and Camacho, A. G. (1986), Data analysis and adjustment of the first geodetic surveys in the Caldera of Teide, Tenerife, Canary Islands. Tectonophysics, $130,213-234$.

Sevilla, M. J. and Romero, P, (1991), Ground deformation control by statical analysis of a geodetic network in the Caldera of Teide, J. Volcanol. Geotherm. Res., 47, 65-74.

Sevilla, M. J., and Sánchez, F. J., Geodetic network for deformation monitoring in the Caldera of Teide, In Proc. 2nd Workshop on European Laboratory Volcanoes, Santorini, Greece, 2-4 May, 1996. (Ed. Casale R., Fytikas M., Sigvaldasson G. and Vougioukalakis G.) (Publ. Europ. Comm. DGXII Environment and Climate Res. Progr., 1996) pp. 615-636.

Sevilla, M.J., Valbuena, J.L., Rodríguez-Díaz, G., and Vara, M.D. (1996), Trabajos altimétricos en la caldera del Teide [Levelling campaigns on the Teide caldera]. Física de la Tierra, 8, 117-130.

Siebert, L., Simkin, T., and Kimberly, P., Volcanoes of the World (University of California Press. University of California Press, California, 2011)

Sigurdsson, H., Houghton, B., McNutt, S.R., Rymer, H., and Stix, J., Encyclopedia of Volcanoes (Academic Press, San Diego, California, 2000)

Suriñach, E. (1986), La estructura cortical del archipiélago canario. Resultados de la interpretación de perfiles sísmicos profundos [Crustal structure of the Canarian Archipelago. Results of deep seismic profiles interpretation], Anales de Física, Serie B, 82, $62-77$. 
Tiampo, K., Rundle, J.B., Fernandez, J., and Langbein, J. (2000), Spherical and ellipsoidal volcanic sources at Long Valley Caldera, California, using a Genetic Algorithm inversion technique, J. Volcanol. Geotherm. Res. 102, 189-206.

Tizzani, P., Manconi, A., Zeni G., Pepe, A., Manzo, M., Camacho, A., and Fernández, J. (2010), Long-term versus short-term deformation processes at Tenerife (Canary Islands), J. Geophys. Res., 115, B12412, doi:10.1029/2010JB007735.

Torroja, J.M. (1926), Nota sobre la triangulación geodésica de primer orden en las Islas Canarias [Note on the first order triangulation network on the Canary Islands], Revista de la Real Academia de Ciencias Exactas, Físicas y Naturales de Madrid, XXIII, pp. 321-322.

Venedikov, A.V., Arnoso, J., Cai, W., Vieira, R., Tan, S., and Vélez, E.J. (2006), Separation of the long-term termal effects from the strain measurements in the Geodynamics Laboratory of Lanzarote. J. Geodyn., 41, 213-220, doi: 10.1016/j.jog.2005.08.029.

Vieira, R., Toro, C., Araña, V. (1986), Microgravimetric survey in the Caldera of Teide, Tenerife, Canary Islands, Tectonophys, 130, 249-257.

Vieira, R., Fernández, J., and Toro, C. (1988), La estación geodinámica de la Cueva de los Verdes (Lanzarote): primeros resultados de las experiencias realizadas [The geodynamic station of Cueva de los Verdes (Lanzarote): first results of the conducted experiencies]. Revista de la Real Academia de Ciencias Exactas, Físicas y Naturales de Madrid, Tomo LXXXII, Cuad. 2, 309-312

Vieira, R., Van Ruymbeke, M., Fernandez, J., Arnoso, J., and Toro, C. (1991a), The Lanzarote underground laboratory, Cahiers Centre Eur. Geodynam. Seismol. 4,71-86

Vieira, R., Fernández, J., Toro, C., and Camacho, A.G. Structural and oceanic effects in the gravimetric tides observations in Lanzarote, In Proc. XI ${ }^{\text {th }}$ Int. Symp. Earth Tides (ed. Kakkuri, J.) . (E. Schweizerbart'sche Verlagsbuchhandlung, Stuttgart, Germany, ISBN: 3510-65148-0, 1991b) pp. 217-230. 
Vieira, R. (1994), La estación geodinámica de Lanzarote [The geodynamical station of Lanzarote]. Serie Casa Volcanes, Cabildo Insular Lanzarote, 3, 31-40.

Vieira, R., Van Ruymbeke, M., Arnoso, J., D'Oreye, N., Fernández, J., and Toro, C., Comparative study of the tidal gravity parameters observed in Timanfaya, Jameos del agua and Cueva de los Verdes stations at Lanzarote Island, In Proc. XII Int. Sym. Earth Tides (Ed. Hsu,H.T.) (Science Press, Beijing, New York, 1995) pp. 41-52.

Vieira, R., Sevilla, M.J., Camacho, A.G., Toro, C., and Martín, M.D. (1996), Geodesia de precisión aplicada al control de movimientos y deformaciones en la Caldera del Teide [Precision geodesy applied to the monitoring of movements and deformations in the Teide Caldera], Anales de Física, Serie B, 82, 110-126.

Waite, G.O., and Smith R.B. (2002), Seismic evidence for fluid migration accompanying subsidence of the Yellowstone caldera. J. Geophys. Res., 107, B9, 2177, doi:10.1029/2001JB000586.

Ward, S.N., and Day, S.J. (2001), Cumbre Vieja volcano-potencial collapse and tsunami at La Palma, Canary Islands, Geophys. Res. Lett. 28, 17, 3397-3400.

Watts, A. B., and ten Brink, U. S. (1989), Crustal structure, flexure, and subsidence history of the Hawaiian Islands, J. Geophys. Res., 94, 10473-10500.

Watts, A.B., Peirce, C., Collier, J., and Henstock, T. R.R.S. Charles Darwin CD82. Cruise Report (Southampton Oceanography Centre, Southampton, UK, 1993)

Watts, A.B. (1994), Crustal structure, gravity anomalies and flexure of the lithosphere in the vicinity of the Canary Islands, Geophys. J. Int. 119, 648-666.

Watts, A.B., Peirce, C., Collier, J., Dalwood, R., Canales, J.P., and Henstock, T.J. (1997), A seismic study of lithospheric flexure in the vicinity of Tenerife, Canary Islands, Earth Planet. Sc. Lett., 146, 431-447. 
Watts, A. B., and Zhong, S. (2000), Observations of flexure and the rheology of the oceanic lithosphere, Geophys. J. Inter., 142, 855-875.

Wicks, C.W., Thatcher, W., Dzurisin, D., and Svarc, J. (2006), Uplift, thermal unrest and magma intrusion at Yellowstone caldera, Nature, 440, 72-75. doi:10.1038/nature04507.

Wu, J.C., and Chen, Y.Q. (1999), Inverse analysis of deformation mechanism by geodetic surveys: a case study, J. Geodyn. 27, 553-565.

Wysession, M. E., Wilson, J., Bartkó, L., and Sakata, R. (1995) Intraplate Seismicity in the Atlantic Ocean Basin: a Teleseismic Catalog, Bull. Seism. Soc. Am., 85, 3, 755-774.

Yu, T.-T., Fernández, J., and Rundle, J.B. (1998), Inverting the parameters of an earthquakeruptured fault with a genetic algorithm, Comput. Geosci. 24, 173-182.

Yu, T. T., Fernández, J., Tseng, C. L., Sevilla, M. J., and Araña, V. (2000), Sensitivity test of the geodetic network in Las Cañadas Caldera, Tenerife, for volcano monitoring. J. Volcanol. Geotherm. Research, 103, 393-407.

Zazo, C., Goy, J. L., Hillaire-Marcel, C., Ghaleb, B., Gillot, P.-Y., Soler, V., Gonzalez, J.A., and Dabrio, C.J. (2002), Marine Sequences of Lanzarote and Fuerteventura Revisited-a Reappraisal of Relative Sea-Level Changes and Vertical Movements in the Eastern Canary Islands during the Quaternary, Quaternary Science Reviews, 21, 2019-2046. 


\section{FIGURE CAPTIONS}

Figure 1. Location map of the Canary Islands and its position relative to the West African coast.

Figure 2. Schematic graph of the first Geodetic Network link of the Canary Islands, made in the 1930s. Stars denote stations where astronomical observations were made. Circles represent the trigonometric First Order stations. Lines represent geodetic observations between the different stations.

Figure 3. Some published models, obtained from gravimetric (and seismic and geological information) presenting Tenerife structure as composed of subhorizontal layers. (a) Modified from main characteristics of Bosshard and MacFarlane (1970), (b) modified main characteristics of Watts et al. (1997), (c) modified from main characteristics of Fernández et al. (2009), and (d) from Camacho et al. (2011a) according to a 3D non-linear inverse approach.

Figure 4. Location of the geodetic network in Las Cañadas, Tenerife island (Sevilla et al., 1986, Yu et al., 2000). Meanings are: 1 . Teide and Pico Viejo craters and basaltic cones; 2 . salic emission centres and domes; 3 . base of the caldera wall; 4 . geodetic station.

Figure 5. Inset: location of geodynamic stations in Lanzarote island; CV Cueva de los Verdes; T Timanfaya. Detailed map: plan of Timanfaya National Park with eruptive fissure of the 17301736 eruption, the primary volcanic cones, and location of Timanfaya station (after Fernández et al. 1992). 
Figure 6. Differential interferogram from Tenerife island corresponding to 2 Aug. 1996-15 Sept.

2000. No fringe can be seen in the Las Cañadas caldera area, so there is no deformation from 2 Aug. 1996-15 Sept. 2000 at the precision level attainable with one interferogram. (1) and (2) represent Garachico (G) and Chío (C) subsidence areas, respectively, from 20 Jul. 1993-15 Sept. 2000 differential interferogram $\left(\mathrm{B}_{\perp}=180 \mathrm{~m}, \Delta \mathrm{d}=2614\right.$ days. $\mathrm{B}_{\perp}$ denotes the perpendicular baseline between the two orbits). The Garachico subsidence has 3 fringes, in other words, about 9 cm of ground subsidence from 20 Jul. 1993-15 Sept. 2000; the Chío subsidence has 1 fringe, that is to say, about $3 \mathrm{~cm}$ of ground subsidence from 20 Jul. 1993-15 Sept. 2000. Red circle indicates the location of Garachico village. LCC indicates the Las Cañadas Caldera area (modified from Fernández et al., 2003; 2004).

Figure 7. Global GPS network defined for Tenerife Island. It is composed by 17 stations from REGCAN95 together with the permanent station TENE, marked with circles. A densification network formed by 2 fourth order stations (C774 and C747) and 2 benchmarks (CLV1 and CLV2) was installed in the zone with greater deformation near Garachico city (modified from Fernández et al., 2004).

Figure 8. Elevation changes for Tenerife Island determined comparing coordinates determined in the different GPS-GNSS surveys (August 2000; July 2001; July 2002; May 2004; July 2005; January 2006). 2004-2006 campaigns were carried out in response to the volcano-tectonic crisis in Tenerife that began in 2004. G denotes location of Garachico city, $\mathbf{C}$ denotes location of Chio deformation area, and $\mathbf{L C C}$ the location of Las Cañadas Caldera.

Figure 9. Epicentral locations of anomalous seismicity registered from 2003 to 2006 for Tenerife Island and surroundings (IGN, 2007). 
Figure 10. SBAS-DInSAR results obtained using 55 radar images acquired from 1992 to 2005 by the ERS sensors from descending orbits. See text and Fernández et al. (2009) for details. (a) Geocoded mean deformation rate map computed in correspondence to coherent pixels only, and superimposed on the DEM of the island; the reported SAR azimuth and range directions (black arrows) are indicative. Blue arrows show the horizontal displacement measured with error ellipses determined using GPS observations between 2000 and 2006 at the stations of the GPS network. The white stars, labeled as “'b", “'c', “'d", “'e'” and 'ff', identify the pixels whose DInSAR LOS deformation time series are shown in panels (b-f); note that in panel (f) the deformation associated to the 2004 seismic crisis has been highlighted in orange. (g) Plot of the mean deformation rate values (for the pixels located in coherent areas) versus topography with the locations of the areas (black letters from ' $\mathbf{b}$ " to 'ff') affected by localized deformation (Fernández et al., 2009).

Figure 11. Spatial distribution of the stations of the Tenerife Permanent GPS network and representation of the significant annual trend values (larger than 2.5 times their standard deviations) for the ITER-PGPS stations in Tenerife. See text for exact values and discussion (Prieto et al., 2005).

Figure 12. (a) Estimated descending linear deformation rate between 2 September 1992 to 8 January 2000. The black rectangle shows the location of the figure inset, which is a zoom into the Montañas del Fuego area (Timanfaya eruptive centers). (b-i) Time series of displacements and associated estimated errors of 8 selected points. See text for details. (González and Fernández, 2011). 
Figure 13. Horizontal (a) and vertical (b) displacements at the GPS geodetic control points between 1994 and 2007 GPS campaigns. (c) Horizontal and (d) vertical displacements between 2006 and 2007 campaigns. The results were obtained using GAMIT software (Prieto et al., 2009).

Figure 14. Stack results shown on a shaded DEM. Differential interferograms were corrected for atmospheric elevation-phase dependence. Results are only from coherent points (pixels), which exhibit LOS linear velocity (positive away from satellite, indicated with the arrows). (a) Stacking of 82 long temporal separation ERS differential interferograms for the period 1992-2000, accompanied by vertical GPS linear velocity between 1994 and 2007. (b) Stacking of 18 long temporal separation ENVISAT differential interferograms for the period 2003-2008.We also show estimates of horizontal GPS linear velocities between 2006 and 2007. Note the linear rate from the 2003 to 2008 results is noisier than the 1992 to 2000 results, mainly due to the smaller dataset, so these results should be considered with caution. The largest magnitude subsidence signal corresponds to the Teneguia volcano (T symbol) (González et al., 2010b).

Figure 15. (a) Observed ground deformation (4 May 2011 to 8 August 2011) using ascending RADARSAT-2 images, with a maximum motion toward satellite of $\sim 9 \mathrm{~cm}$. (b) Simulated ground deformation predicted by the best-fitting single spherical source model (see panel g) of Figure 15a. (c) Residual of Figures 15a and 15b. (d) Observed ground deformation (31 August 2011 to 30 October 2011) using descending ENVISAT images from Track 109, with a maximum motion toward the satellite of $\sim 10-12 \mathrm{~cm}$. (e) Simulated ground deformation predicted with the bestfitting single spherical source model (see panel $\mathbf{g}$ ) of Figure 15d. (f) Residual of Figures 15a and 15b. (g) Location of the best-fitting spherical point sources: orange, deep crustal source (Figure 15b); and dark red, the shallower crustal reservoir (Figure 15e). Seismicity flux (events/ $\mathrm{km}^{2}$ ), which represents the 2-D clustering of background seismicity, is shown the background. Inset 
shows the vertical cross section b-b'. (h) Time series of the volume change between May 2011

Figure 16. (a) Coherence map for interferogram 20061221_20070301. Figure is in radar adquisition coordinate system. (b) Google maps image of Fuerteventura. It can be noticed how sand dunes areas are completely decorrelated. (c) Geocoded mean LOS velocity map computed by stacking.

Figure 17. Fast response continuous GPS networks to the El Hierro eruption: a) IGN; b) INVOLCAN (ITER and Nagoya University), and c) IGN and INVOLCAN networks. Both networks use data provided by a publicly available GPS station, FRON (installed by GRAFCAN, blue circle). As we can see, none of the initiatives decided to install a station close to a publicly available one, and meanwhile decided to install stations in close proximity to other locations, which overall do not contribute to maximize the monitoring capabilities. 


\section{TABLE CAPTIONS}

Table 1. List of interferograms, with their spatial baselines, used in the A-DInSAR study of the Fuerteventura Island. 


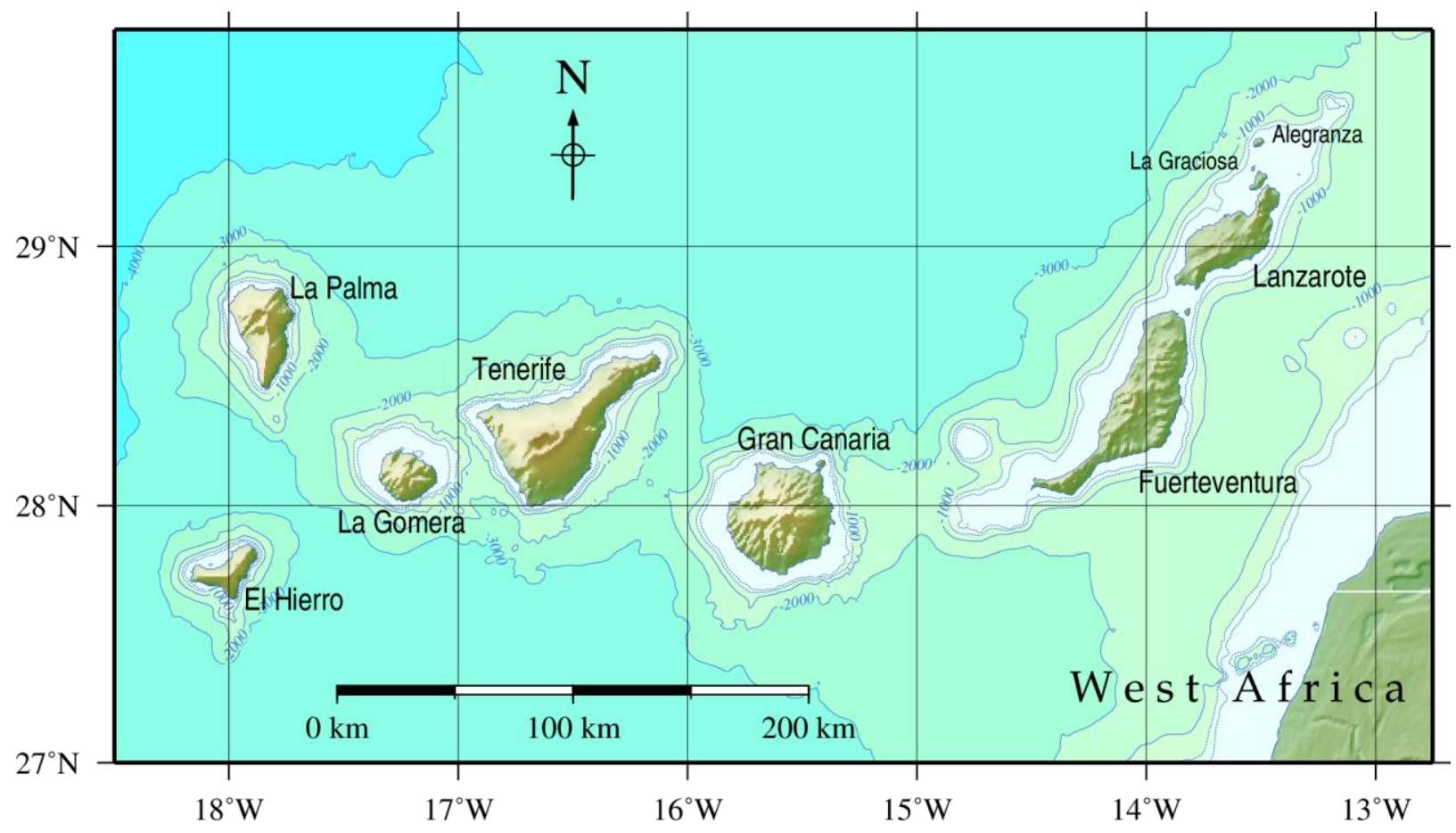

Figure 1 


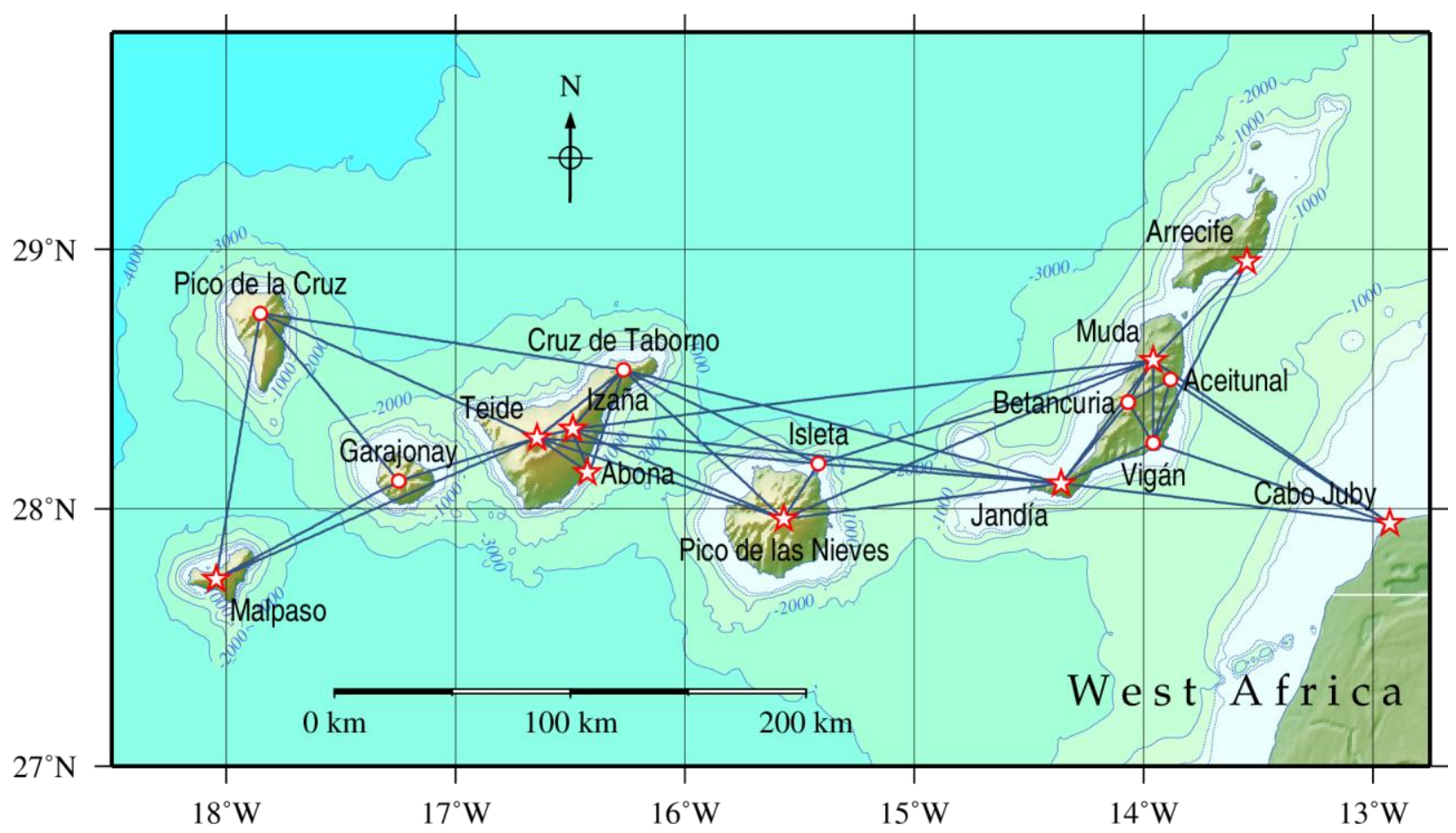

Figure 2 

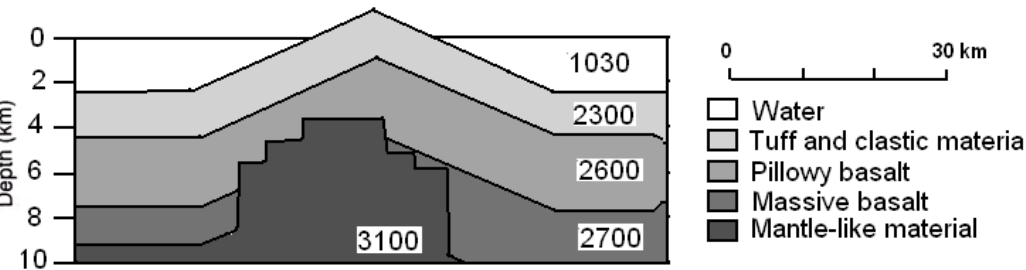

(a)
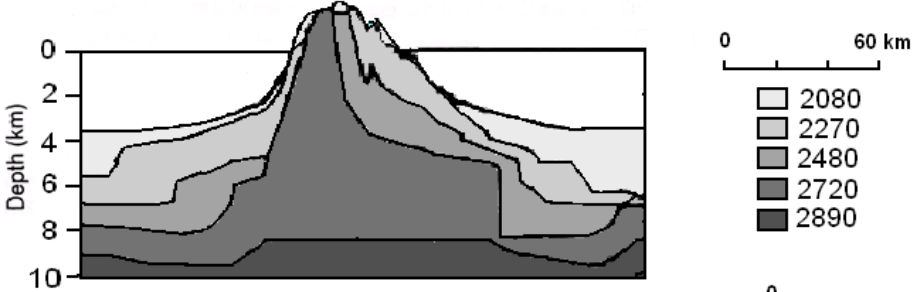

(b)

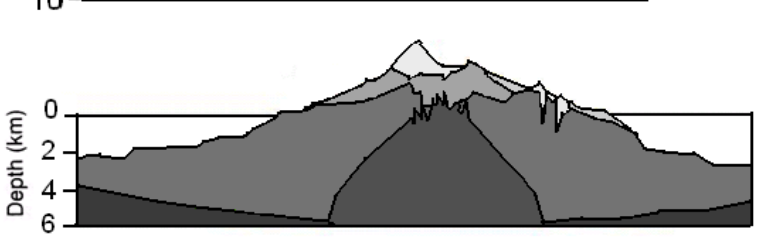

$\stackrel{0}{ } \quad 1 \quad 30 \mathrm{~km}$ $\square$ Teide complex $\square$ Modern series $\square$ Cañadas Series (post erosional)

(c) $\square$ Basalt (shield)

Cumulitic \&

$$
\text { dike complex }
$$
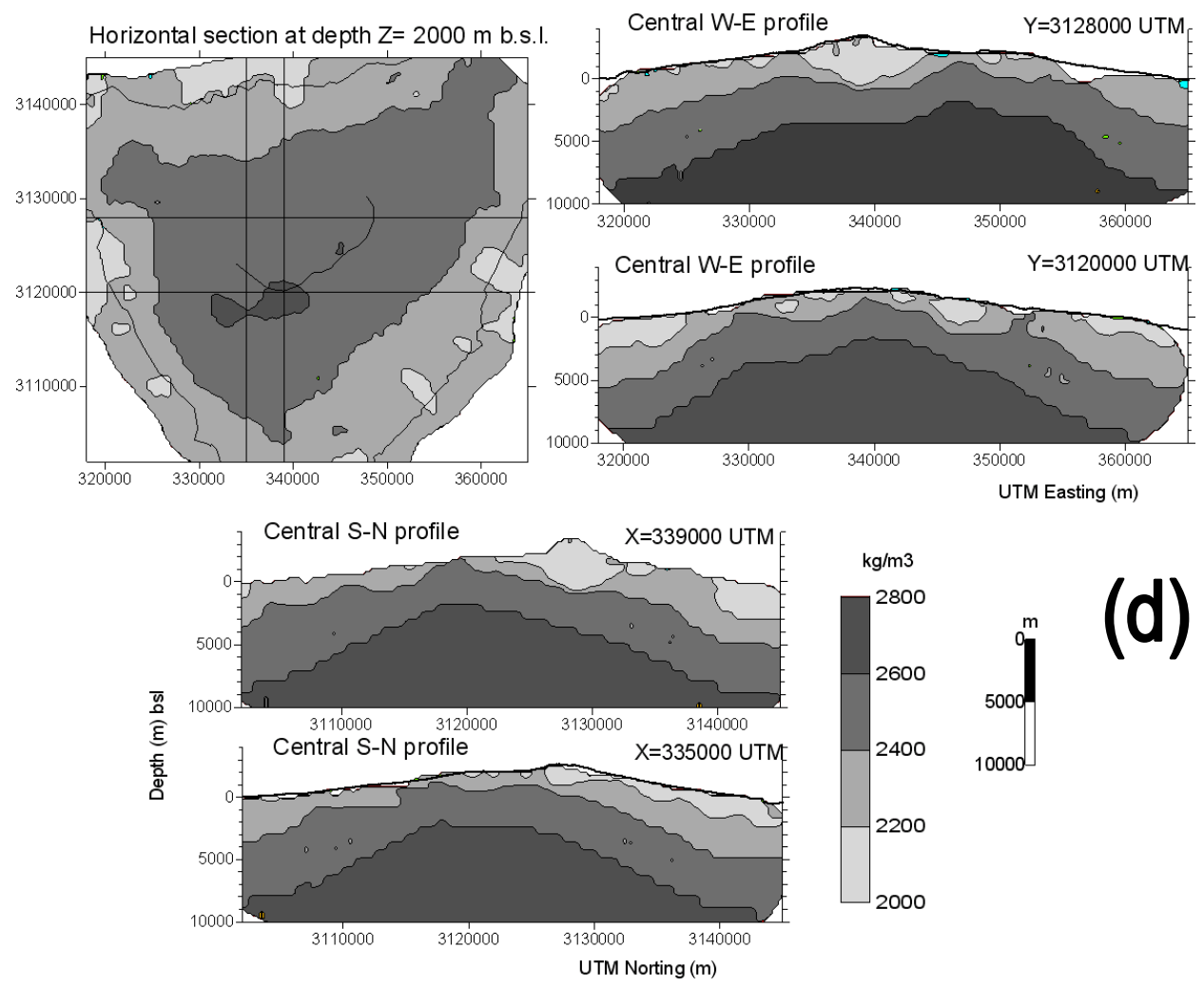

(d)

Figure 3 


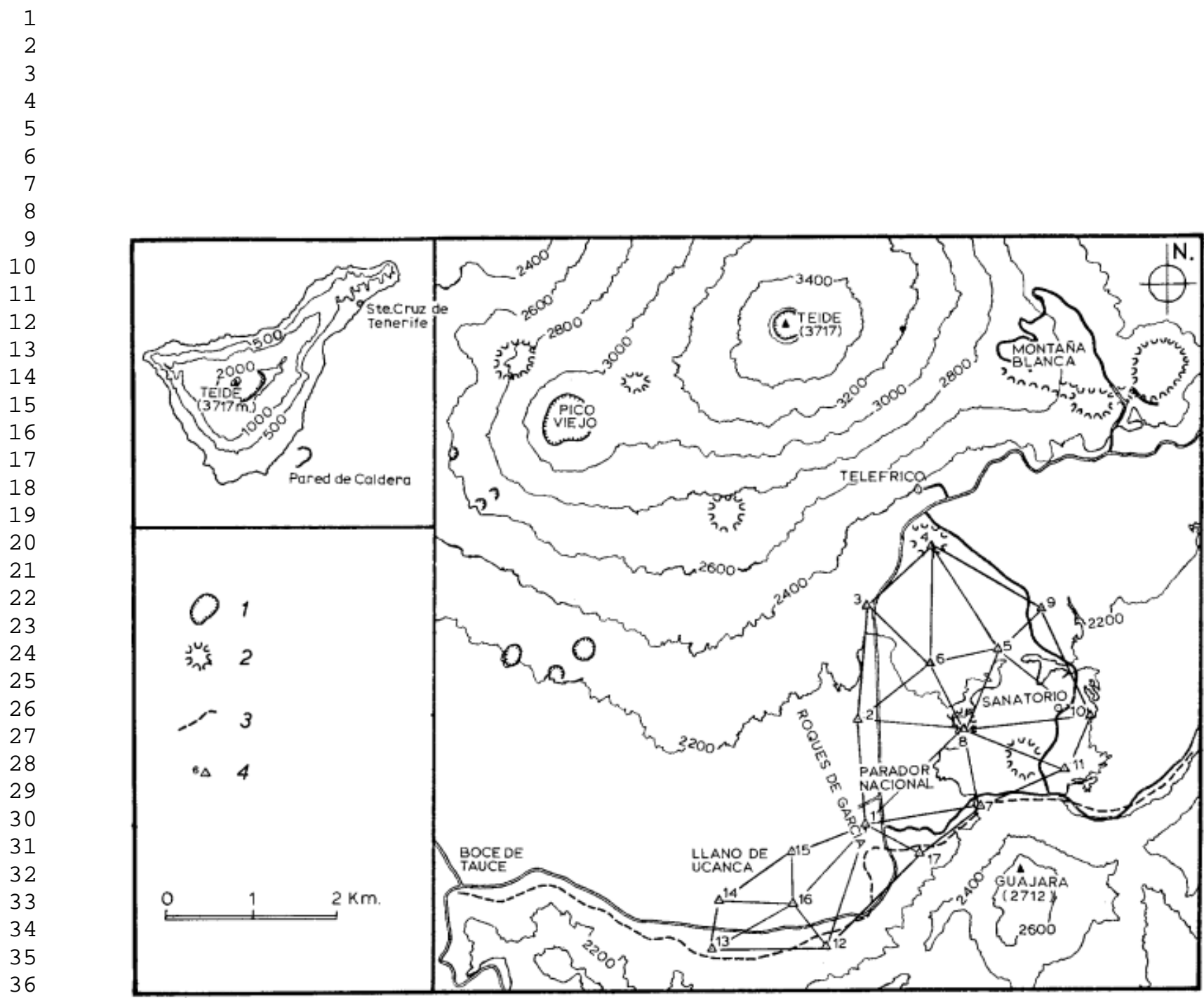

Figure 4 


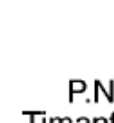

P.N.
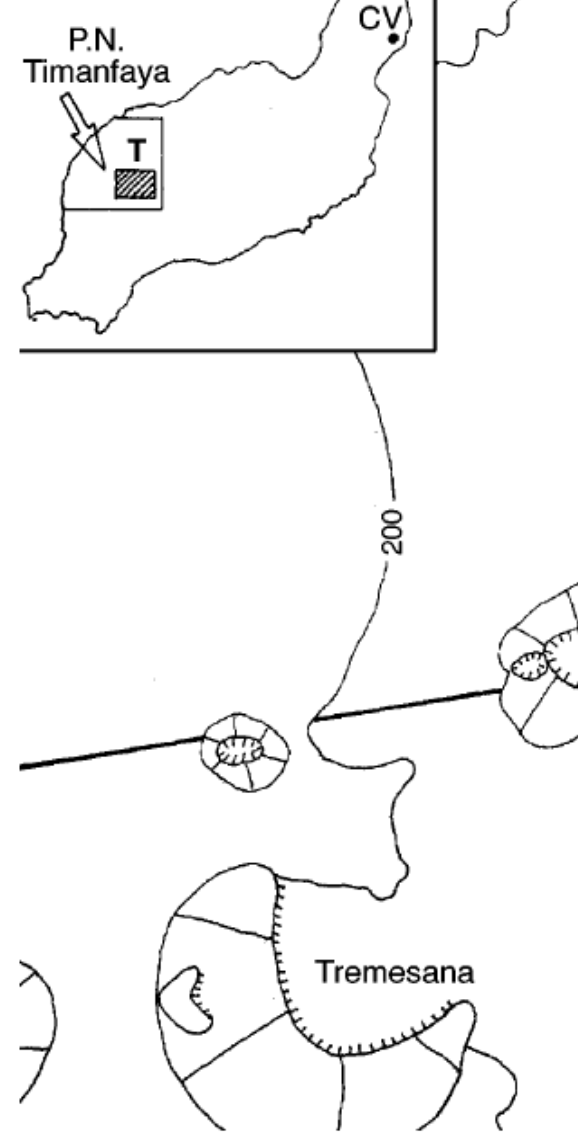

오

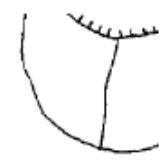

Chinyero

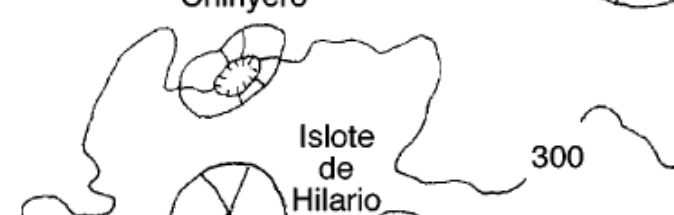
Montaña Rajada Hilario
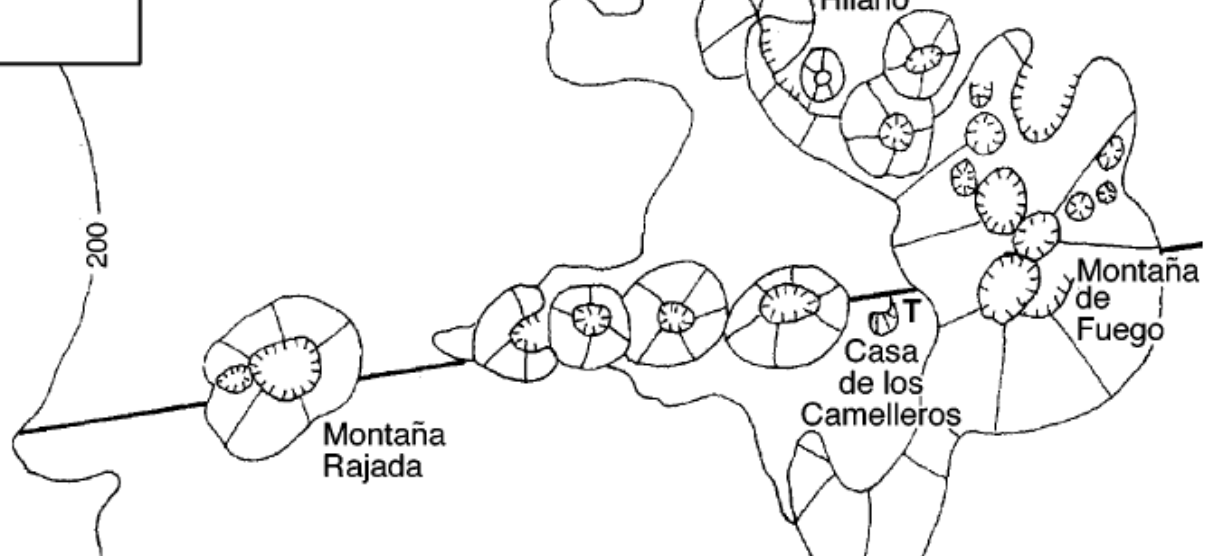

Figure 5 


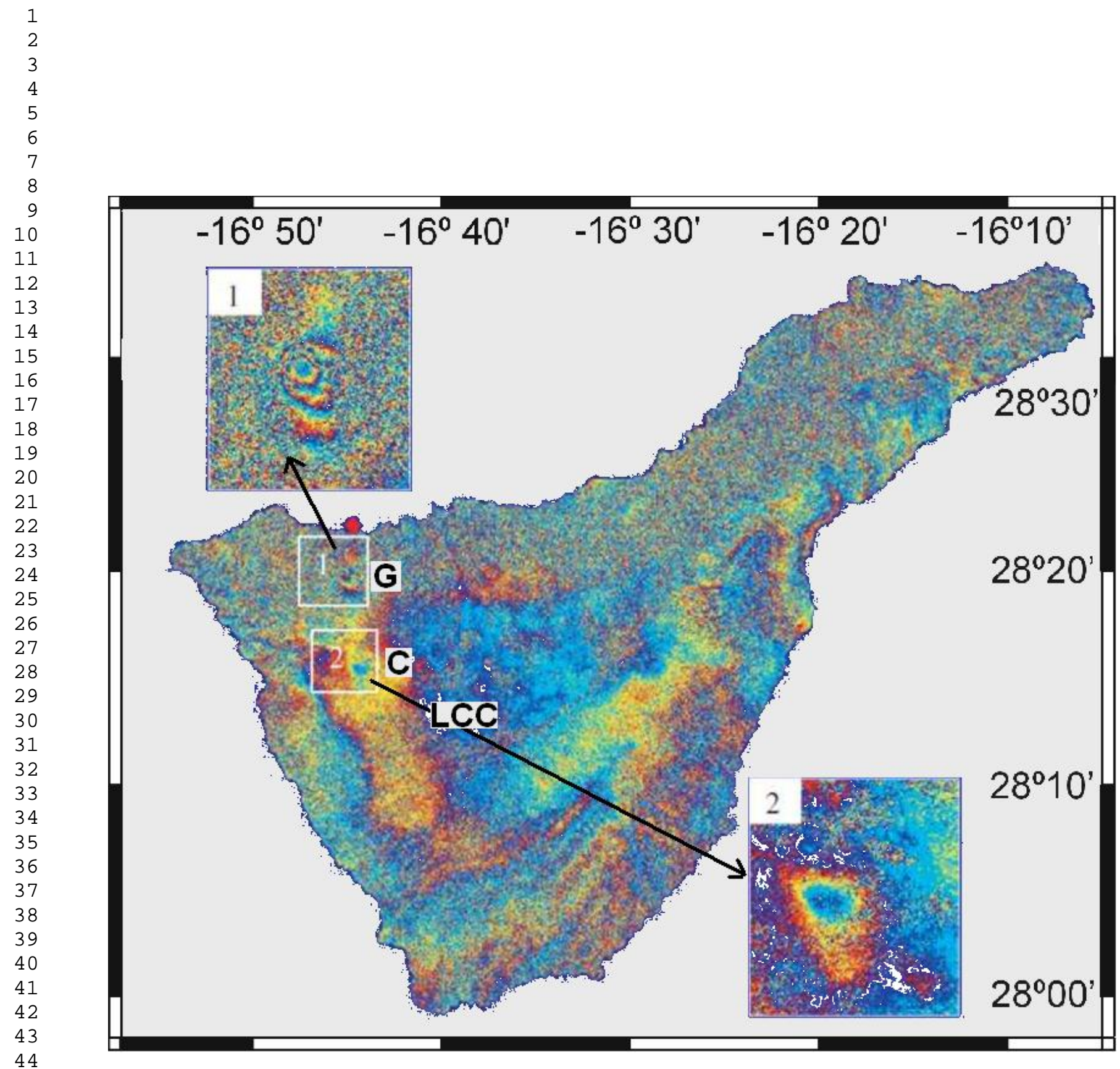

Figure 6 


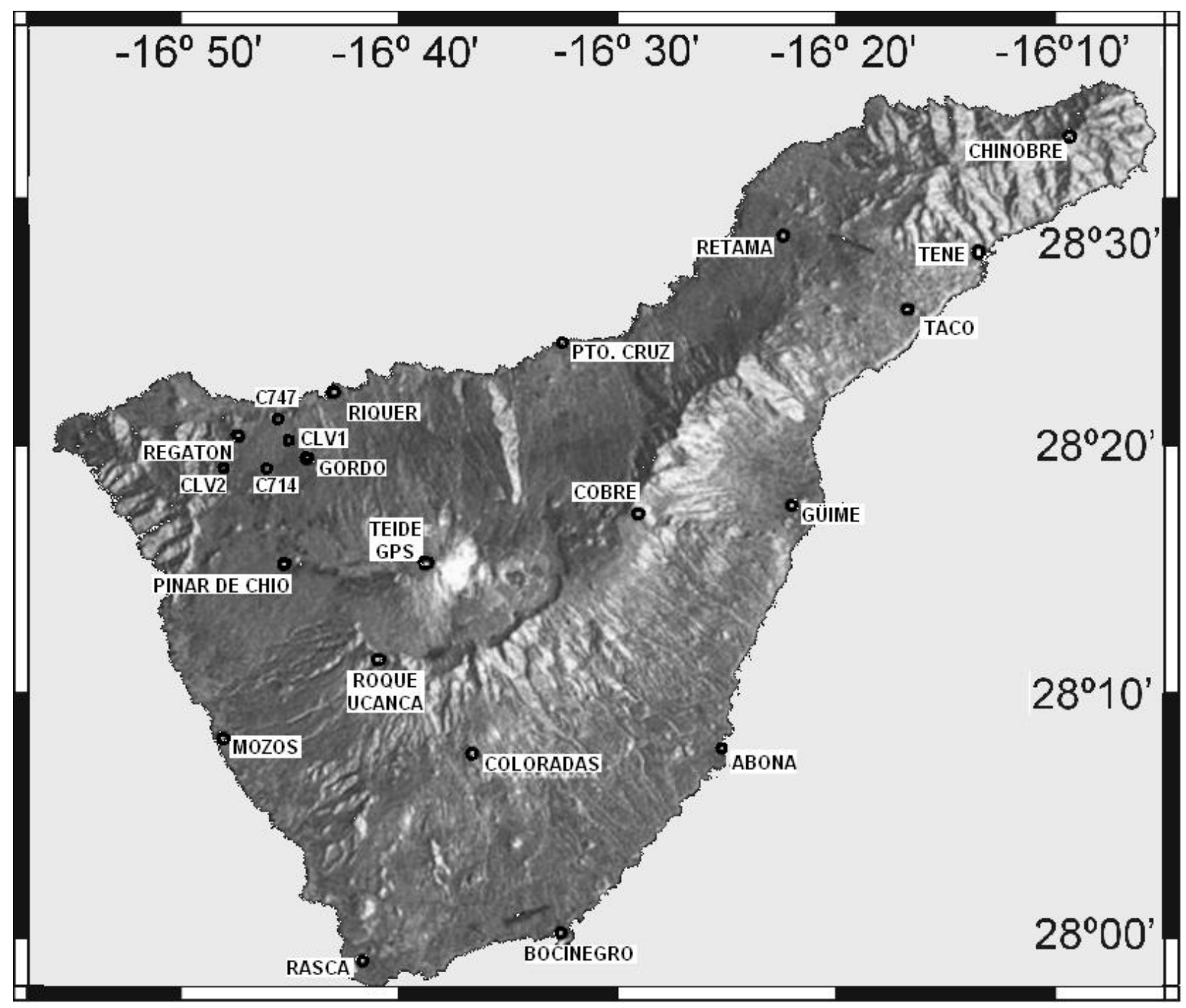

Figure 7 
1

2
3

4

5

6

7

8

9
10

11

12

13

14

15

16

17

18

19

20

21

22

23

24

25

26

27

28

29

30

31

32

33

34

35

36

37

38

39

40

41

42
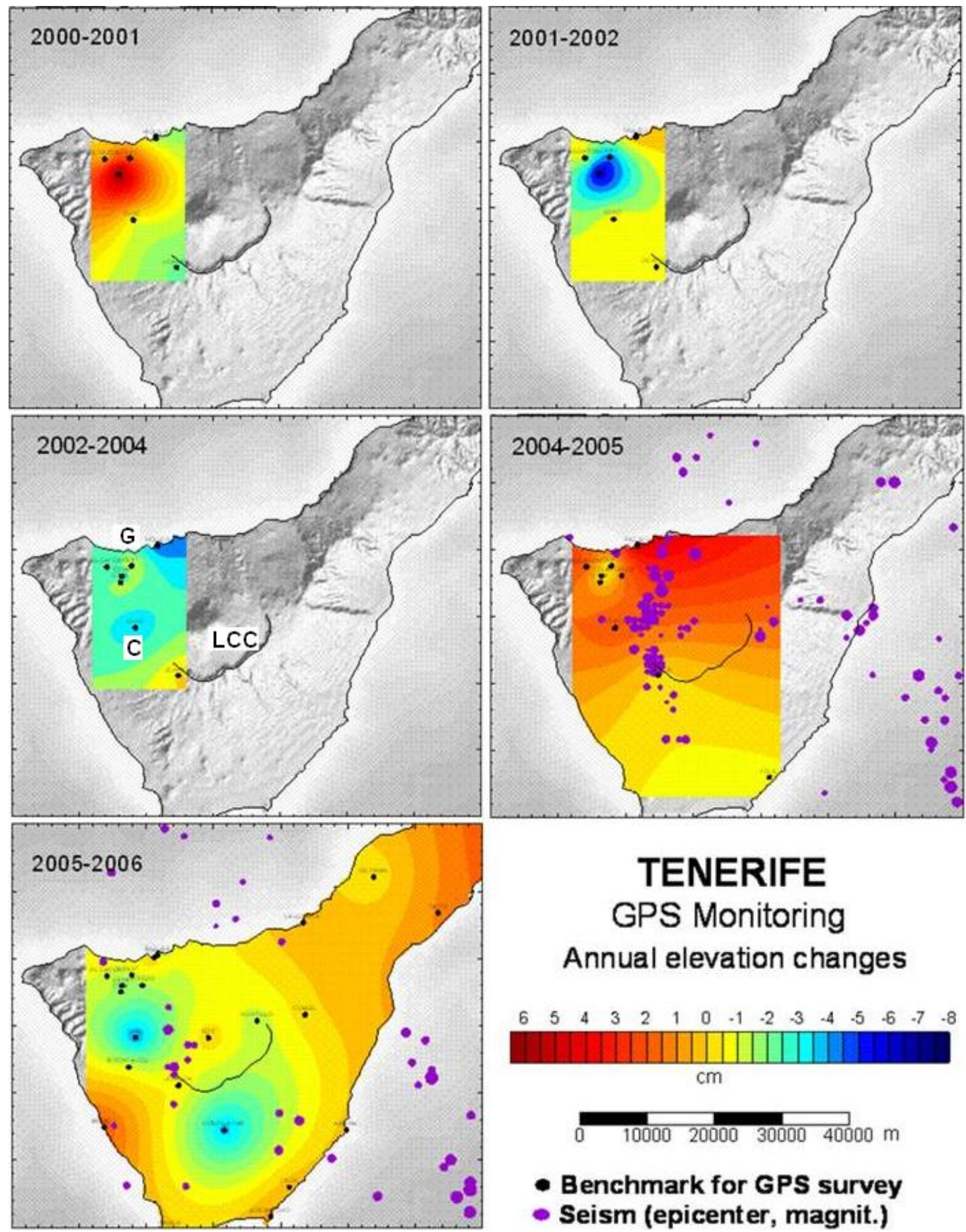

TENERIFE GPS Monitoring Annual elevation changes

$\begin{array}{lllllllllllllll}6 & 5 & 4 & 3 & 2 & 1 & 0 & -1 & -2 & -3 & -4 & -5 & -6 & -7 & -8\end{array}$

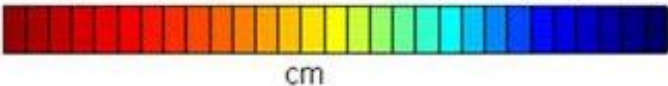

$0 \quad 1000020000 \quad 3000040000 \mathrm{~m}$

- Benchmark for GPS survey

- Seism (epicenter, magnit.)

Figure 8 


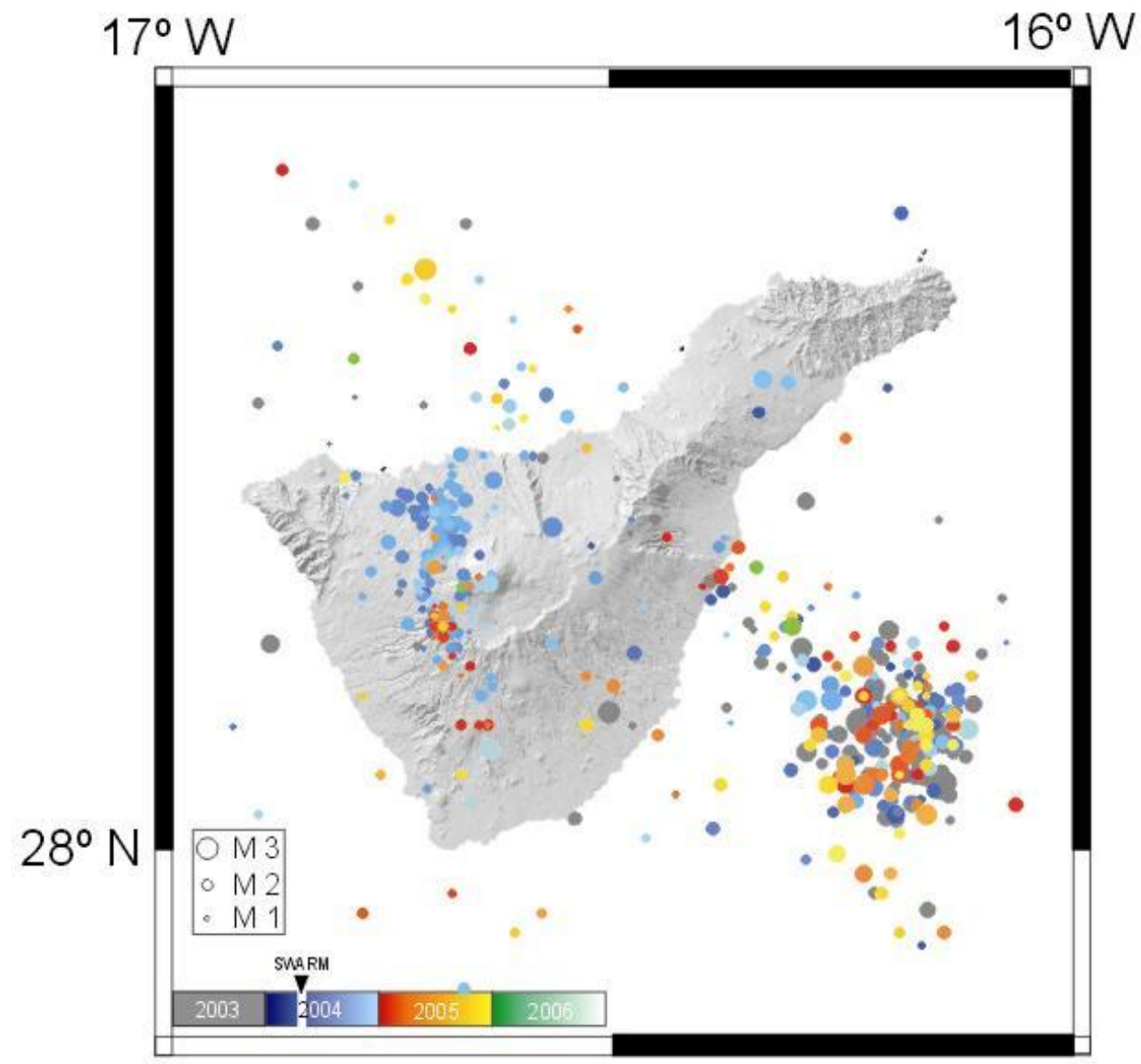

Figure 9 


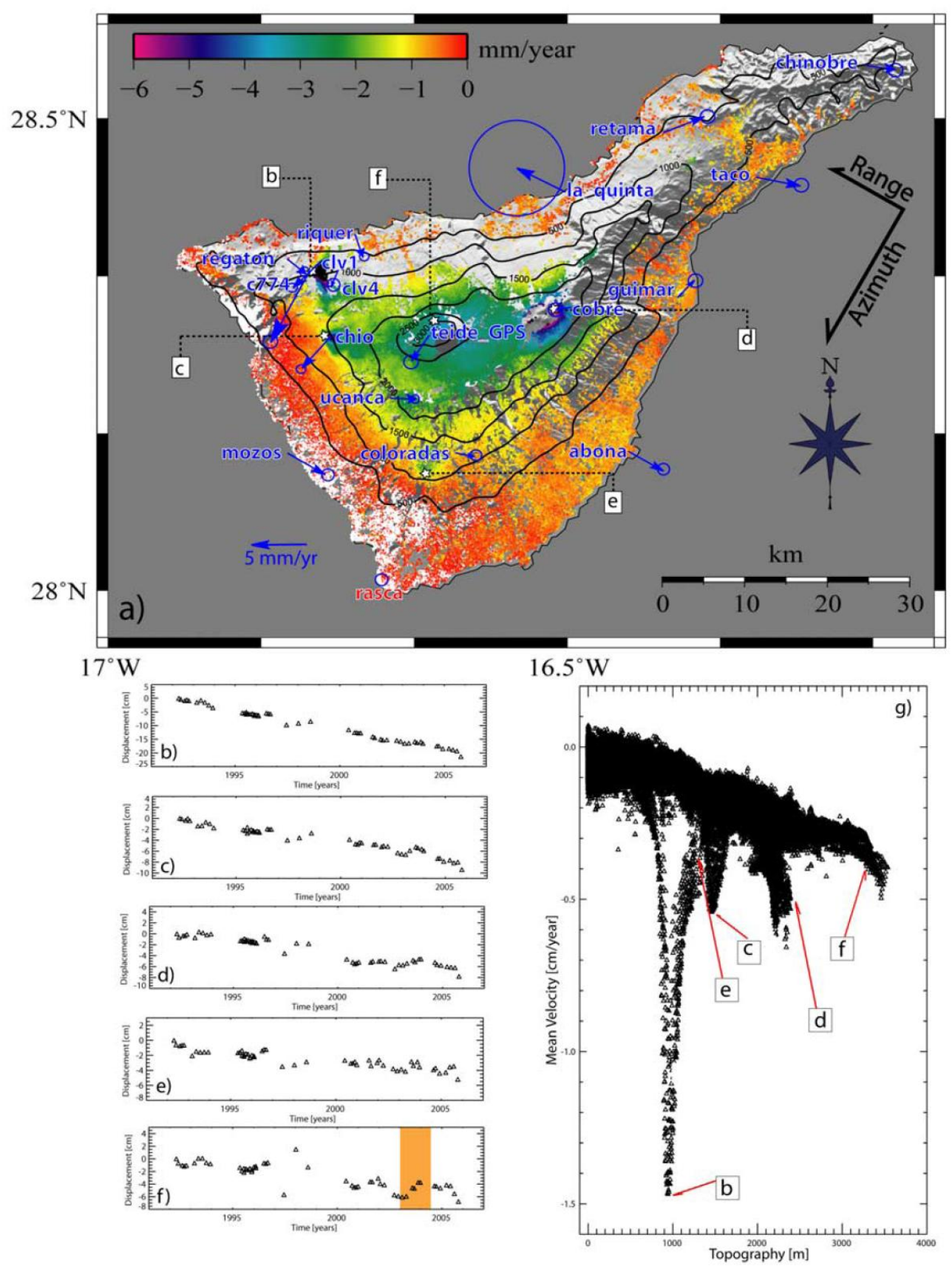

Figure 10 


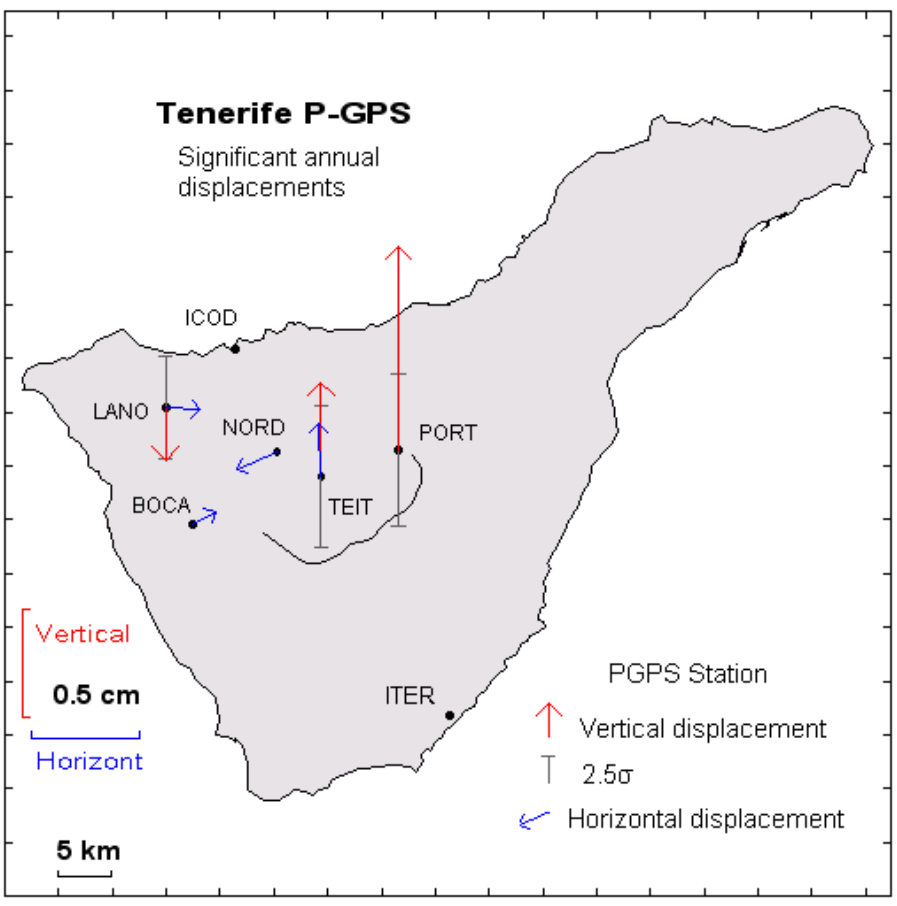




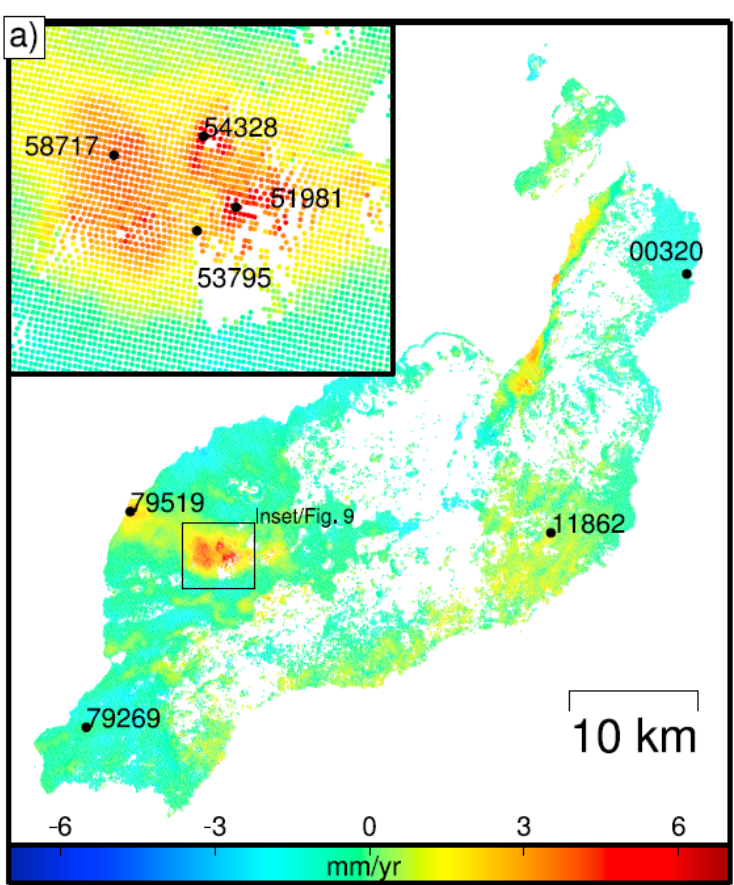

b)
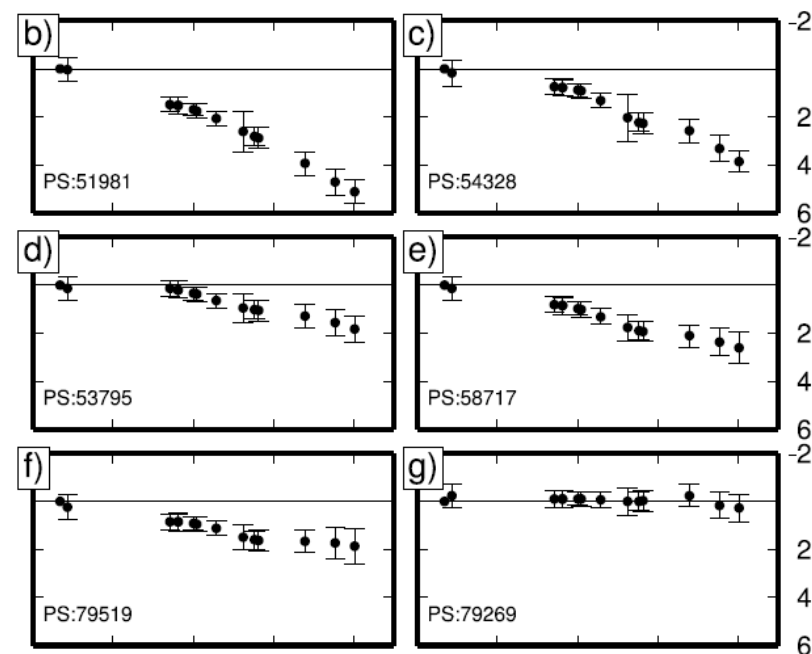

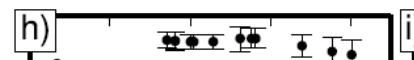

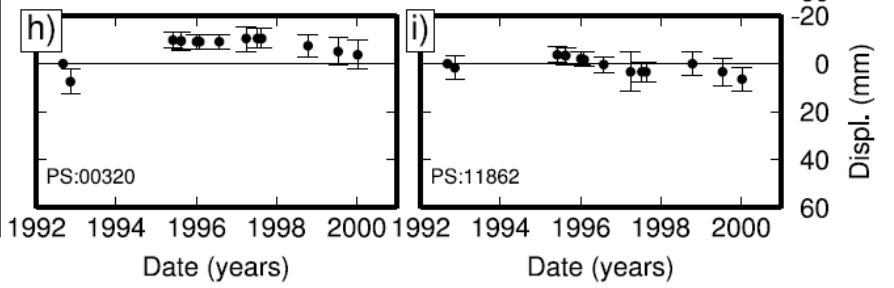

\section{Figure 12}



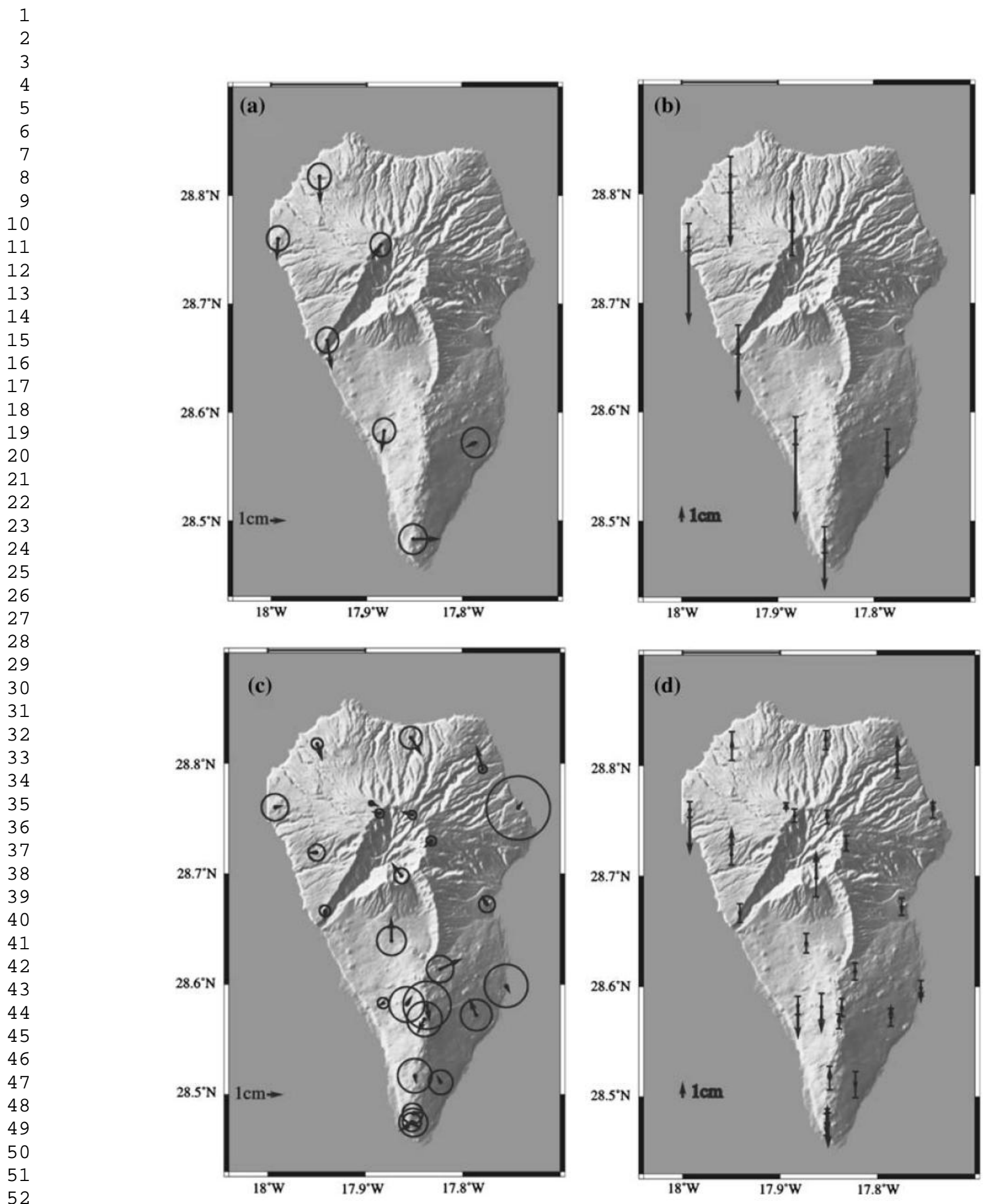

Figure 13 

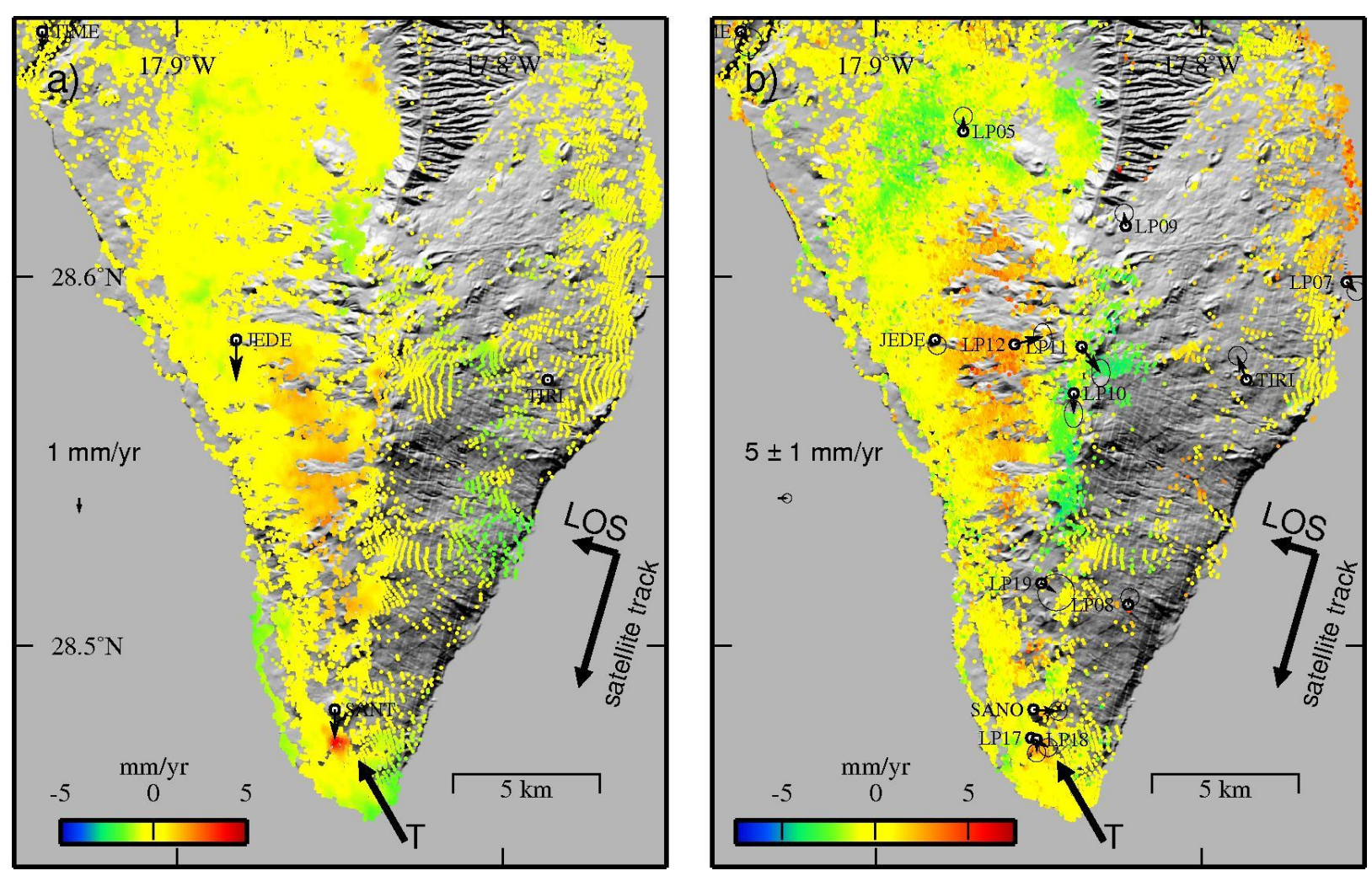

Figure 14 

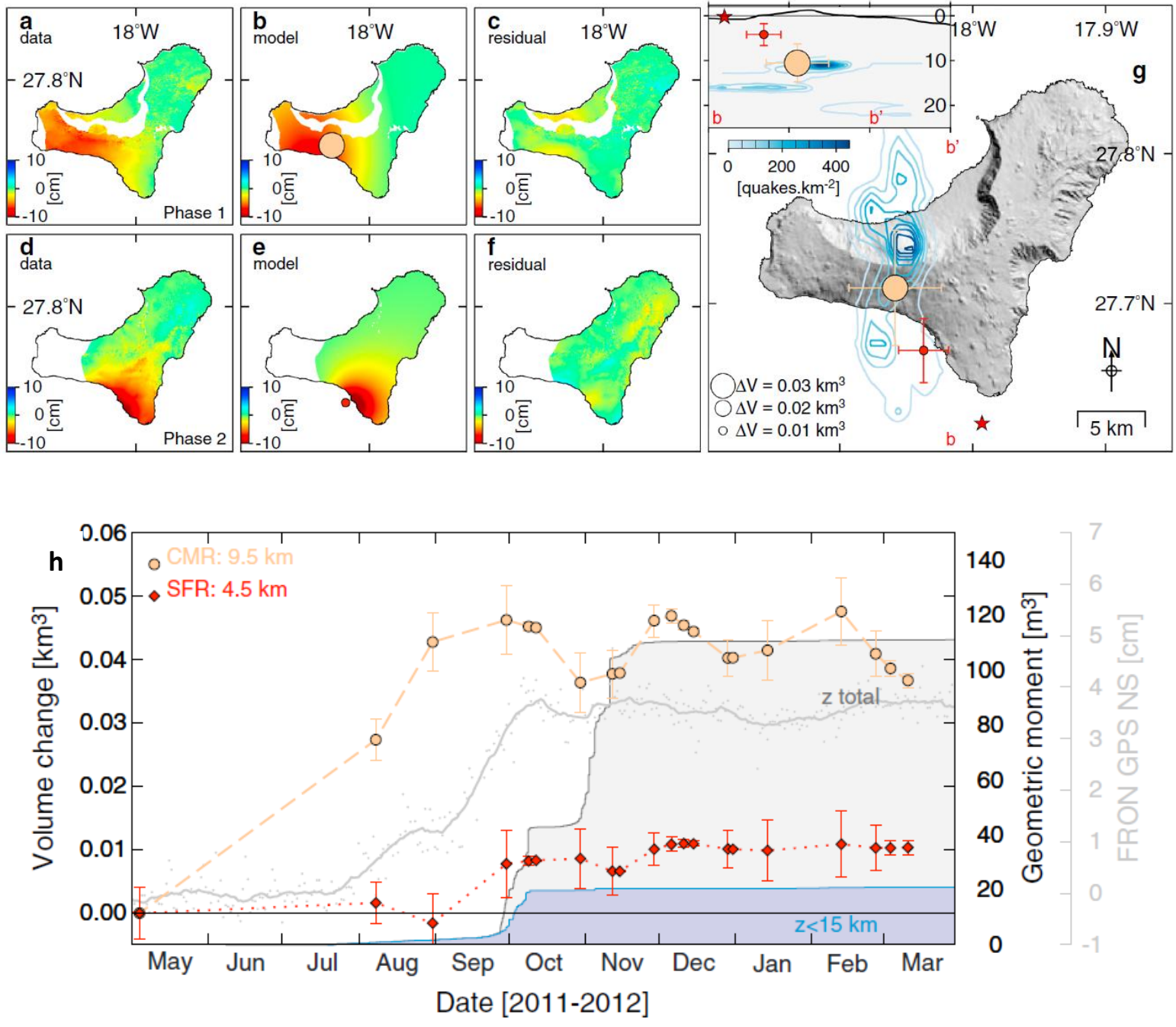

Figure 15 
1

2

3

4

5

6

7

8

10

11

12

13

14

15

16

17

18

19

20

21

22

23

24

25

26

27

28

29

30

31

32

33

34

35

36

37

38

39

40

41

42

43

44

45

46

47

48

49

50

51

52

53

54

55

56

57

58

59

60

61

62

63

64

65
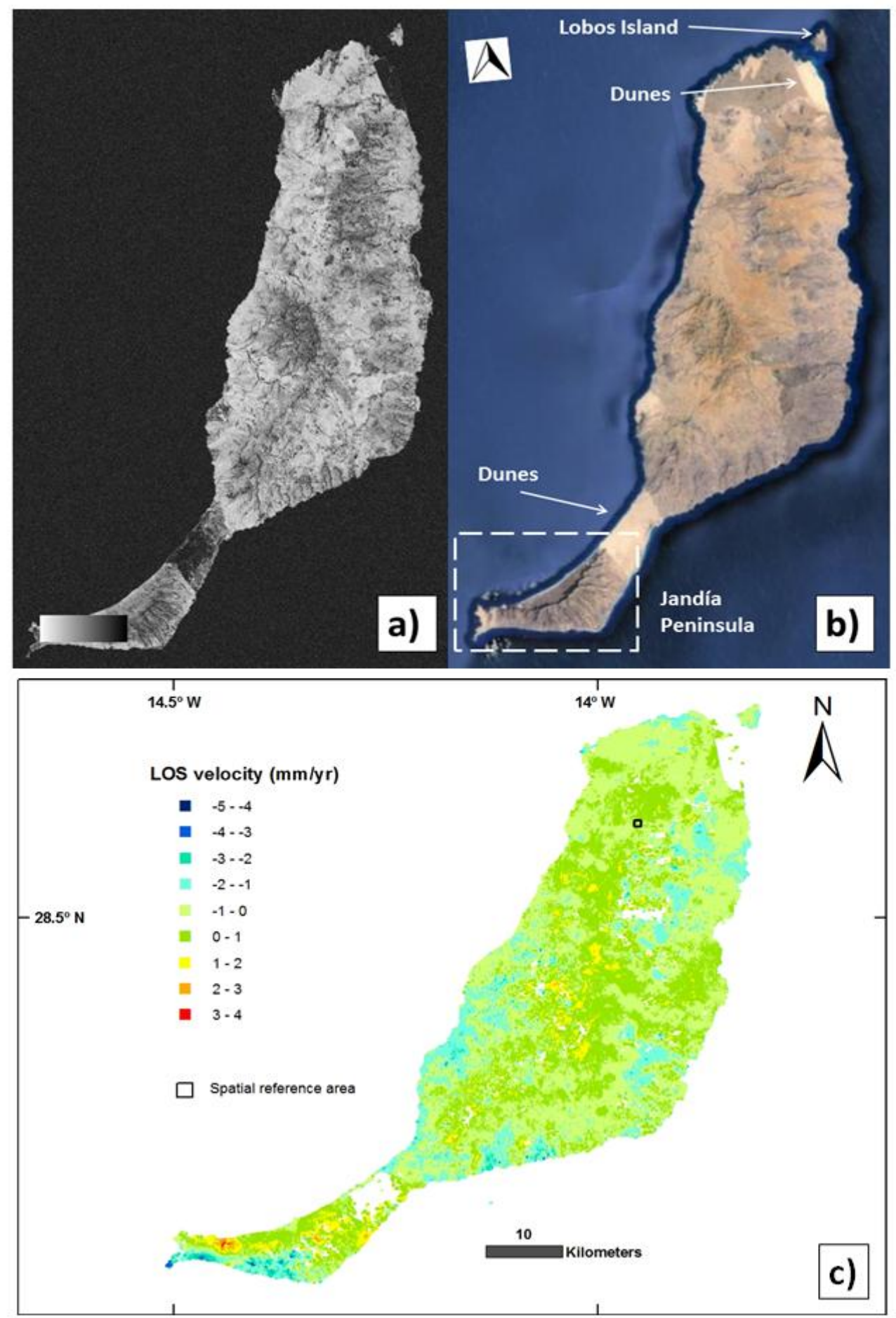

Figure 16 

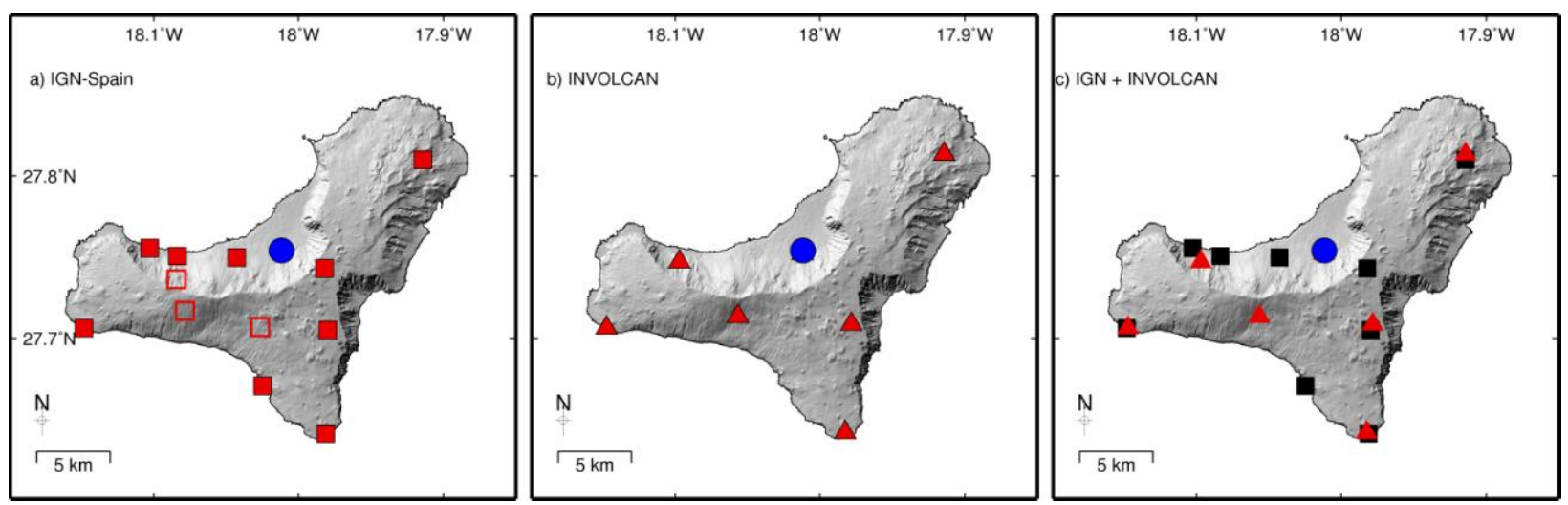

Figure 17 
Table 1

1

2

\begin{tabular}{|c|c|}
\hline List of Interferograms & Spatial Baselines (meters) \\
\hline $20031023-20050505$ & 111.7 \\
$20031023-20060629$ & 143.6 \\
$20041111-20061116$ & -58.7 \\
$20050120-20060525$ & -394.5 \\
$20050120-20061221$ & 233.0 \\
$20050120-20070301$ & 301.8 \\
$20050505-20060629$ & 31.9 \\
$20050505-20060803$ & 326.9 \\
$20050922-20060420$ & -70.7 \\
$20050922-20060907$ & 124.1 \\
$20050922-20061221$ & -68.8 \\
$20050922-20070301$ & 0.0 \\
$20050922-20090827$ & -8.7 \\
$20060316-20060420$ & 14.8 \\
$20060316-20061221$ & 16.7 \\
$20060316-20091105$ & -5.1 \\
$20060420-20060907$ & 194.8 \\
$20060420-20061221$ & 1.9 \\
$20060420-20070301$ & 70.7 \\
$20060420-20090827$ & 62.0 \\
$20060420-20091105$ & -19.9 \\
$20060525-20061116$ & -342.0 \\
$20060525-20070125$ & 81.4 \\
$20060525-20080424$ & 253.5 \\
$20060525-20090129$ & 143.0 \\
$20060629-20060907$ & -449.0 \\
$20060907-20061221$ & -192.9 \\
$20060907-20070301$ & -124.1 \\
$20060907-20090618$ & 15.6 \\
$20060907-20090827$ & -132.8 \\
$20061012-20070125$ & -138.4 \\
$20061012-20080424$ & 33.7 \\
$20061012-20090129$ & -76.8 \\
$20061221-20070301$ & 68.8 \\
$20061221-20080424$ & -374.0 \\
$20061221-20090827$ & 60.1 \\
$20061221-20091105$ & -21.8 \\
$20061221-20100114$ & -116.1 \\
$20070125-20090129$ & 61.6 \\
$20070301-20090618$ & 139.7 \\
$20070301-20090827$ & -8.7 \\
$20070301-20091105$ & -90.6 \\
$20080424-20090129$ & -110.5 \\
$20090827-20091105$ & -81.9 \\
$20091105-20100114$ & -94.3 \\
$20100114-20100218$ & \\
\hline
\end{tabular}

